WISSENSCHAFTSZENTRUM BERLIN FÜR SOZIALFORSCHUNG

SOCIAL SCIENCE RESEARCH CENTER BERLIN

\author{
Jonathan Beck * \\ Fixed, Focal, Fair? \\ Book Prices Under Optional Resale Price \\ Maintenance
}

* WZB - Wissenschaftszentrum Berlin

SP II $2004-15$

December 2004

ISSN Nr. $0722-6748$

Research Area

Markets and Political Economy

Research Unit

Competitiveness and Industrial Change
Forschungsschwerpunkt

Markt und politische Ökonomie

Abteilung

Wettbewerbsfähigkeit und industrieller Wandel 
Zitierweise/Citation:

Jonathan Beck, Fixed, Focal, Fair? Book Prices Under

Optional Resale Price Maintenance, Discussion Paper SP

II 2004 - 15, Wissenschaftszentrum Berlin, 2004.

Wissenschaftszentrum Berlin für Sozialforschung gGmbH,

Reichpietschufer 50, 10785 Berlin, Germany, Tel. (030) 25491 - 0

Internet: www.wz-berlin.de 


\section{Fixed, Focal, Fair? Book Prices Under Optional Resale Price Maintenance}

by Jonathan Beck*

In media markets, products are highly differentiated but prices are often bunched at apparent focal points. I use a comprehensive cross-section data set on the German book market to assess whether such focal points are a result of upstream coordination and whether the option to impose resale price maintenance (RPM) played a facilitating role. Therewith, I provide empirical evidence to a long-lasting policy debate. Results suggest that focal prices are used to coordinate competition rather than collusion. Focal prices are mostly lower than expected from hedonic projections. In cases where the decisions on focal pricing and RPM are positively correlated, controlling for endogeneity and a number of other factors, RPM does not seem to facilitate above average focal pricing in particular.

Keywords: resale price maintenance; focal prices; vertical restraints; collusion; simultaneous probit; book industry.

JEL Classification: D4, L11, L13, L42, L82.

Thanks to Lars-Hendrik Röoller for guidance and comments, to Joe Clougherty, Ela Glowicka, Michal Grajek, Peter Haan, Holger Stichnoth, Henning Weber and participants at the BDPEMS workshop and the WZB seminar for comments and helpful discussions, to MVB Marketing- und Verlagsservice des Buchhandels $\mathrm{GmbH}$ for its permission to use the data and in particular toWilfried Schinzel for his advice on data characteristics and extraction. Reinhard Kraasch provided me with a program to process the database's output files. Financial support from the German Federal Ministry of Education and Research is gratefully acknowledged (project 01AK702A). All remaining errors are mine. 


\section{Fixiert, fokal, fair? Buchpreise bei optionaler Preisbindung}

Produkte in Medienmärkten sind hochgradig differenziert, Preise sammeln sich jedoch häufig an augenscheinlich fokalen Punkten. Ich verwende einen umfassenden Satz von Querschnittsdaten aus dem deutschen Buchmarkt, um zu untersuchen, ob derartige Fokalpunkte das Ergebnis von Koordination auf der Verlagsseite sind und ob optionale Preisbindung eine begünstigende Rolle dabei spielte. Damit bereichere ich eine langlebige Politikdebatte mit empirischer Evidenz. Die Ergebnisse legen nahe, dass Fokalpreise eher der Koordination von Wettbewerb als Kollusion dienen. Fokalpreise sind meistens niedriger als von hedonischen Projektionen erwartet. In den Fällen, in welchen die Entscheidungen über fokale Preissetzung und Preisbindung positiv korreliert sind, unter Kontrolle des Einflusses von Endogenität und einer Reihe von anderen Faktoren, scheint optionale Preisbindung die Setzung von überdurchschnittlichen Fokalpreisen nicht insbesondere zu begünstigen. 


\section{Focal pricing in media industries}

Every month, book publishers introduce thousands of new titles to the market - titles which differ greatly in various cost- and demand-specific aspects. Pricing, however, is less heterogeneous. Certain prices, in particular those close to or at round numbers like 20 or 25 , appear far more often than others. Some suspect that publishers could use such prices as focal points - in the sense of Schelling (1963) - to coordinate competition to the disadvantage of consumers. The music industry is another case in point. Reviewing proposed mergers of major record companies, the European Commission found that at a predominant share of record sales took place at a small set of distinct wholesale prices. ${ }^{1}$ The Commission's concern was that these prices served as focal points for tacit collusion among the majors. In addition, the majors publicly announce changes in pricing, which can also be interpreted as a sign of collusion (Rotemberg and Saloner, 1990). ${ }^{2}$ In Sony/BMG, however, the Commission concluded that the empirical evidence pointing towards tacit collusion on focal prices was insufficient to prohibit the merger.

Making first-time use of comprehensive title-specific data on the German book market, this paper has two objectives. First, I provide an empirical assessment whether coordinated focal pricing occurs in the book industry and whether it harms consumers. Second, I analyze the determinants of focal pricing: focussing in particular on the influence of resale price maintenance (RPM) as an endogenous decision variable. Thereby, this paper provides broad empirical evidence to a long-lasting policy debate on RPM for books. ${ }^{3}$

In many European countries, that debate began in the 19th century with the introduction of RPM schemes to the book market. ${ }^{4}$ It has been reoccurring regularly, in recent years mostly because some of these RPM systems were subject to inquiry by the Euro-

\footnotetext{
${ }^{1}$ See Rabassa (2001) and the Commission's documentation of the EMI/Time Warner and the Sony/BMG merger cases (COMP/M.1852 and COMP/M.3333).

${ }^{2}$ For example, Universal Music recently announced to cut its wholesale prices "to \$ 10.02 or $\$ 9.09$ for many of the CDs it produces" and said that it expected competitors to follow (Financial Times, Sept. 4, 2003).

${ }^{3}$ To my knowledge, there is no other quantitative empirical study on the price effects of RPM for books except for case studies involving a handful of titles (Stumpp, 1998; Liefmann, 1904). Bittlingmayer (1992) and Clerides $(2001,2002)$ are empirical studies regarding other aspects of the industry. Ornstein and Hanssens (1987) study the effects of RPM in liquor dealing.

${ }^{4}$ For reviews of the national experiences, see Pohle (1895) and Picot (1991) for Germany, Guillebraud (1965) for the UK and Tosdal (1915) for a US perspective. The introduced scheme mostly took the form of a sectoral contractual arrangement like the UK's Net Book Agreement. While the latter was abolished in 1995, some other countries still maintain a comparable scheme. Alternatively, RPM for books is often allowed or even enforced by a distinct law like France's Loi Lang.
} 
pean Commission. Although cross-border trade was the critical issue in all recent cases, involved parties tended to debate the overall costs and benefits of RPM for books. ${ }^{5}$ The ability of RPM to enable or facilitate collusion between publishers represents a major concern, raised in the general economic literature on RPM as well as in these particular debates. ${ }^{6}$ Another stream of theoretical literature emphasizes potential efficiency benefits of RPM in the presence of upstream market power and demand uncertainty (Deneckere et al., 1996, 1997; Wang, 2004). The welfare implications of these RPM theories are often ambiguous, though. In conclusion, a case-by-case empirical analysis is frequently called for (Martin, 1993; Butz, 1996, for example).

In this paper, I propose a formalization of focal pricing in media industries which leads to an empirical method based on hedonic regression to identify its average effect on price levels. Empirical results employing a comprehensive database of "books in print" suggest that coordinated focal pricing is prevalent in a number of market segments. Since my data were generated under an RPM system where publishers had the choice not to fix a title's retail price, I can use title-specific information on this choice to assess the level effects of focal pricing under RPM. Results indicate that focal pricing under RPM rarely damages consumer surplus: i.e., it most often does not lead to higher prices on average.

In a second step, I explicitly account for the simultaneity between the decisions to price focally and to fix the retail price. I also assess the influence of other factors on both decisions. Results regarding RPM reflect those from the first-stage analysis. I cannot confirm the suspicion that RPM facilitates coordination on 'unfair' focal prices - prices that are too high compared to otherwise similar but non-focally priced titles. In segments where the decisions on RPM and focal pricing are positively correlated, this leads significantly more often to 'fair' focal prices - prices with negative 'focality markups' over the (predicted) hedonic price. In segments with predominantly positive 'focality markups', the two decisions are independent. Further results indicate that focal pricing is nevertheless a result of publisher coordination. Alternative causes for observed focal prices points do

\footnotetext{
${ }^{5}$ Inquiries by the Commission concerned cross-border RPM arrangements covering the Netherlands/Belgium, the UK/Ireland, France/Belgium and Germany/Austria, see Goyder (1998).

${ }^{6}$ See Mathewson and Winter (1998) for a survey, Jullien and Rey (2000) for the - to my knowledge - only formal attempt to formulate the suspicion, and $\operatorname{OECD}(1997, \mathrm{p}$. 7ff.) for its application to the book market. The seminal papers on this issue are Yamey (1954) and Telser (1960).
} 
not appear relatively important. In combination, these results suggest that it is competitors who 'meet' on a focal price point, not conspirators.

The rest of the paper is organized as follows: in the next section I give a description of the data and motivate my analysis by a glance at the distribution of book prices in Germany. In section 3 I review related theoretical literature and propose a theoretical framework for the empirical analysis of focal pricing with differentiated products. In section 4 an approach to first measure the price effects of focal pricing and then to assess the influence of RPM, coordination incentives and other factors on focal pricing is presented together with the corresponding results. I also discuss limitations and report on a number of robustness checks. In section 5 I offer some final conclusions.

\section{A first look at the data}

Figure 1: Prices in 'popular' segments by 1-digit level

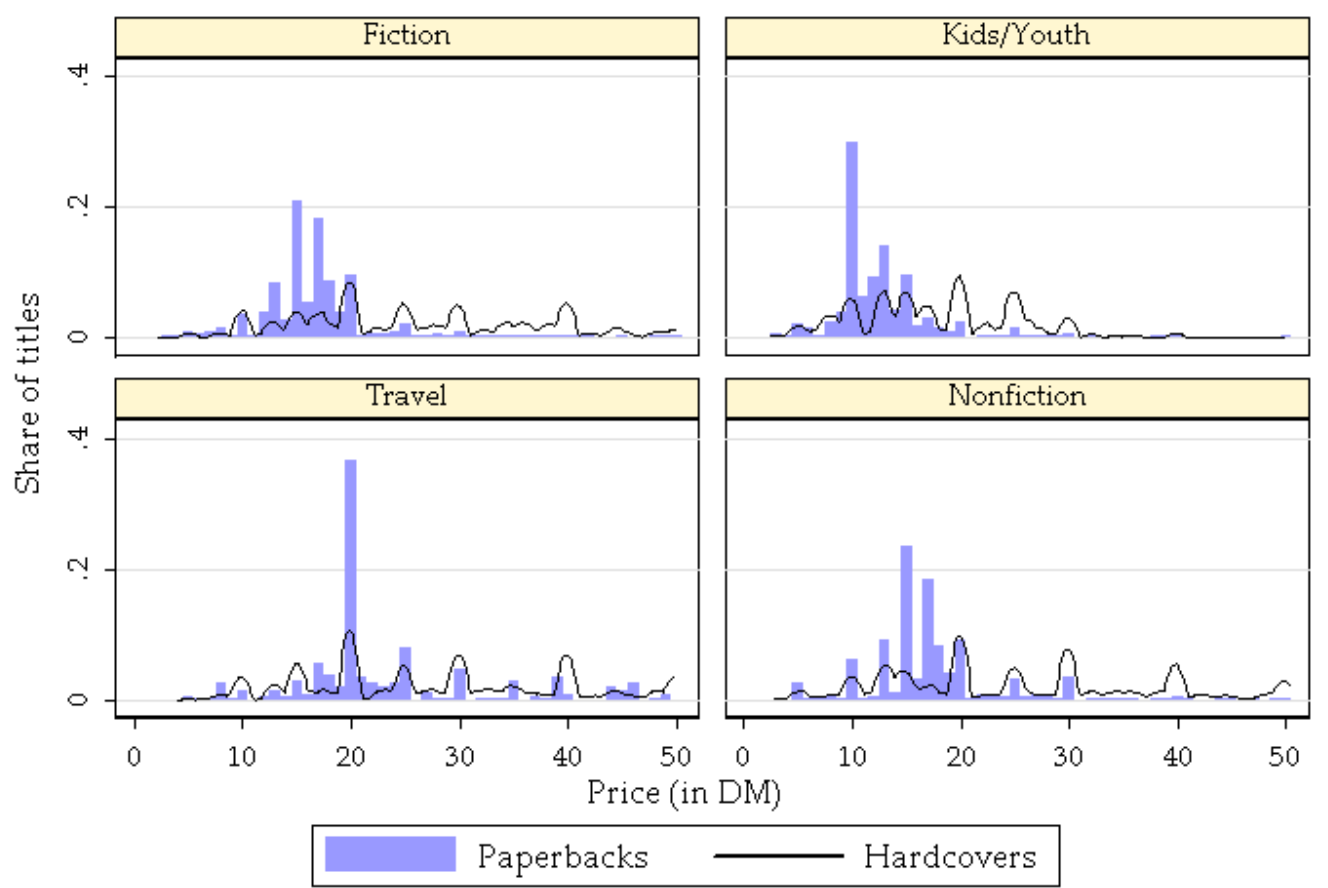

Figures 1 and 2 show the distribution of German book prices below 50 DM (Deutsche Mark), ${ }^{7}$ separately for hardcovers and paperbacks in eight thematic segments. To facilitate comparison, hardcover prices are given as kernel density estimates, while paperback

\footnotetext{
${ }^{7}$ About $70.5 \%$ of all hardcovers and $98.2 \%$ of all paperbacks in the sample have a price in this range.
} 
prices are given as histograms. Binwidth for both histograms and kernels is $1 \mathrm{DM}$. For the histograms, the starting value is 0.5 DM. Effectively, this divides up the observed price range into clusters of $1 \mathrm{DM}$ centered around whole numbers. ${ }^{8}$

Figure 2: Prices in 'professional' segments by 1-digit level

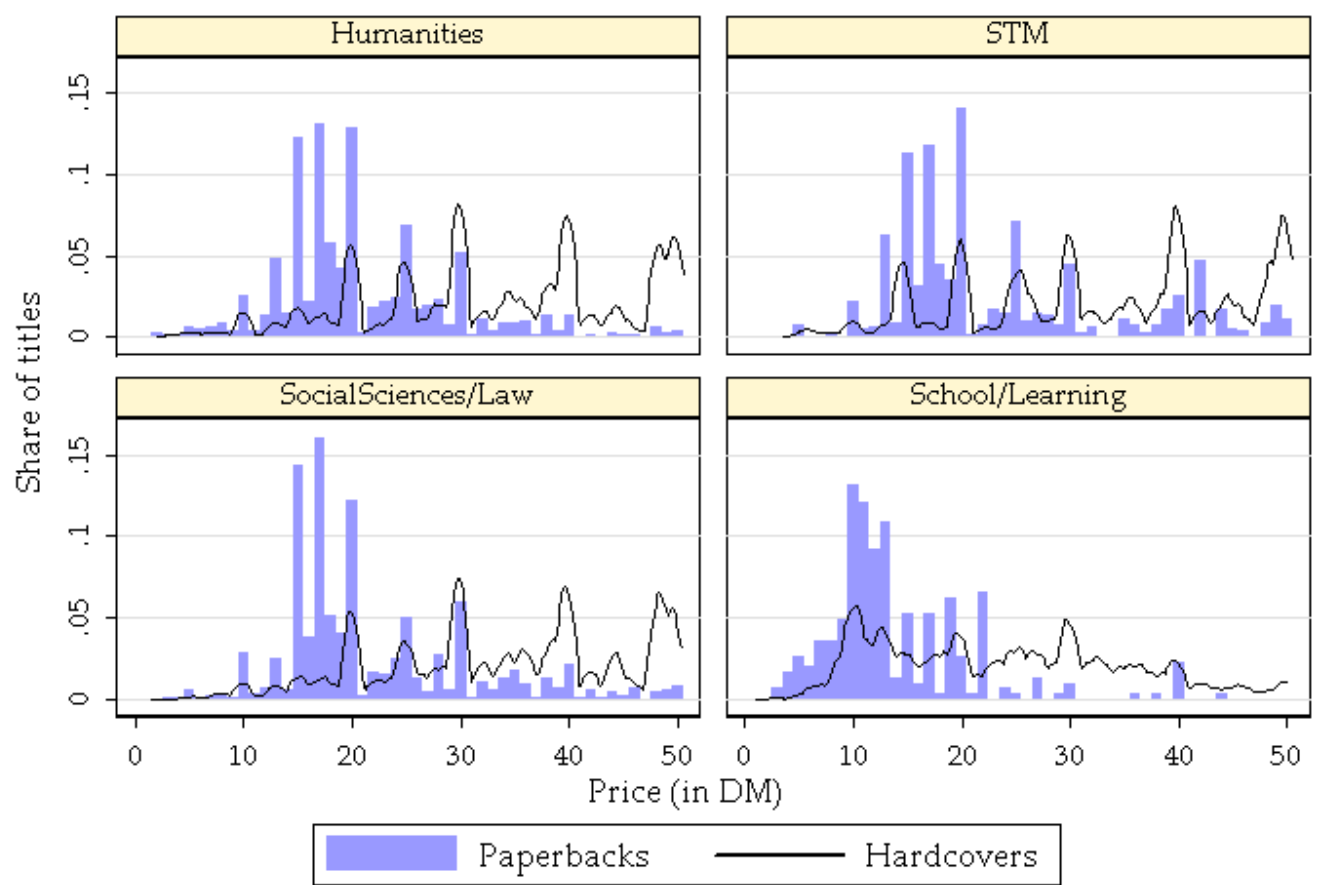

Altogether, these figures confirm that the distribution of book prices exhibits significant mass points at candidate focal points like 10, 15, 20 and so forth. In addition, pricing in hardcover and paperback segments appears to be substantially different: the paperbacks' distributions are by far more compressed. Paperback prices concentrate mostly in the 1020 DM interval, with remarkable bumps at 10,13, 15, 18 and 20 DM. Hardcover prices are higher and mostly concentrate at whole tenners. With relative frequencies around $30 \%$, paperback titles in the segments Travel and Kids/Youth seem to be most outstandingly priced on the focal points 10 and $20 \mathrm{DM}$, respectively.

The data underlying these figures come from the database German books in print which contains information on all titles available in Germany at a certain point in time. It is used

\footnotetext{
${ }^{8}$ This paper is not concerned with the question why prices often end with a nine, although this is true for many titles in the sample as well as for potentially focal prices like 19.90. This phenomenon has been labeled 'the 9 fixation' in the marketing literature, which proposed several explanations. Mostly, they use notions of bounded rationality, where consumers are, for example, subject to rounding illusions, or like to get some change at the cashier. See Basu (1997), whose explanation rests on fully rational consumers, and the references therein. Here, I assume that consumers round rationally and treat prices like 19.90 and 20.00 as roughly equal.
} 
primarily by retailers and librarians, e.g. for keyword searches for specific titles upon consumer request. My sample should carry all titles that were commercially available by about August 2001. I restrict attention to 112,662 titles produced from 1999 with nonmissing observations on price, number of pages, type of binding and market segment. ${ }^{9}$

Data on product characteristics also include dummies indicating whether a title has black or colored images, whether it is published within a series, or whether it is a reprint. Prices that are not subject to RPM are indicated as "free". These are publishers' list prices that publishers demand for direct orders and suggest to retailers. Given the prevalence of RPM, retailers are likely to implement publishers' prices even when they are not subject to RPM, and offer discounts only to sell off remnants. ${ }^{10}$

Market segments are classified in quite some detail through a 3-digit code of the form $x y z$, where every digit stands for another dimension of segmentation:

- the first digit $(x)$ distinguishes hardcover $(x=1)$ from paperback $(x=2)$ titles,

- the second digit $(y)$ denotes one of eight main market segments (see table 1),

- the third digit $(z)$ denotes further sub-segments for every main market. ${ }^{11}$

Thus, the first digit refers to a material characteristic which - as the empirical results below show - also differentiates market segments. The other two digits refer to a thematic classification which applies to both hardcover and paperback titles. For example, $x y z=112$ denotes the following segmentation: hardcover $(x=1)$ fiction $(y=1)$, subcategory thriller $(z=2)$. Table 1 gives some summary statistics for prices in the eight main market segments. I refer to these segments, distinguished by $y$, as '1-digit segments' and to the more detailed segments indicated by $x y z$ as '3-digit' segments. Mean hardcover prices in the popular (mass market) segments 1 to 4 are considerably lower than in the professional publications segments 5 to $8 .{ }^{12}$

\footnotetext{
${ }^{9}$ Some titles were indicated to include another medium such as a CD, CD-ROM or DVD. These titles were excluded from the sample, since it is unclear which of the bundled media was the main product and which the supplement. In addition, non-book market segments (e.g. maps), segments containing less than 5 titles, as well as titles from publishers producing less than 5 titles between 1999 and 2001 were excluded.

${ }^{10}$ While existent in the time period studied here, the possibility to set non-binding suggested retail prices has been eliminated by a new law on RPM for books effective from October 2002, which generally requires publishers to implement RPM.

${ }^{11}$ The original database contains a fourth digit, which allows for a deeper segmentation. I do not make use of this 4-digit segmentation, however, since segments on this level are defined only for a subset of all 3-digit segments and because they often include a small number of titles (or none at all).

${ }^{12}$ The last segment (8) contains mainly schoolbooks and is thus exceptional, since those are usually not purchased by individuals, but mostly in bulk by public institutions that the same time define curricula,
} 
Table 1: Mean hardcover and paperback prices in DM by 1-digit segment

\begin{tabular}{lcccc}
\hline 1-digit segment & $\begin{array}{c}\text { Segment } \\
\text { Size }\end{array}$ & $\begin{array}{c}\text { Share } \\
\text { hardcovers }\end{array}$ & $\begin{array}{c}\text { Average price } \\
\text { hardcovers }\end{array}$ & $\begin{array}{c}\text { Average price } \\
\text { paperbacks }\end{array}$ \\
\hline $\begin{array}{l}\text { Popular segments: } \\
\text { 1: Fiction }\end{array}$ & 20744 & 0.59 & 28.73 & 16.61 \\
2: Kids/Youth & 10553 & 0.79 & 18.47 & 12.41 \\
3: Travel & 4560 & 0.83 & 33.04 & 23.72 \\
4: Nonfiction & 13898 & 0.87 & 31.76 & 18.22 \\
Professional segments: & & & & \\
5: Humanities & 24615 & 0.87 & 67.02 & 23.76 \\
6: STM & 9910 & 0.93 & 108.70 & 38.94 \\
7: Social Sciences/Law & 21490 & 0.93 & 70.68 & 28.92 \\
8: School/Learning & 6892 & 0.96 & 26.95 & 14.37 \\
\hline Total & 112662 & 0.83 & 53.78 & 19.58 \\
\hline
\end{tabular}

Coming back to figures 1 and 2: it is unclear how to interpret them. Are these price distributions outcomes of tacitly collusive pricing, where publishers coordinate on focal price points in order to achieve higher total prices? Or might it be the case that $30 \%$ of all paperback titles in the travel segment have similar cost attributes, or are published by the same large - or even dominant - firm with a uniform pricing policy? In addition, dividing the book market into eight broad thematic segments may not be sufficiently detailed the above figures may hide dense price points in more narrowly defined segments. I approach these questions empirically in section 4 , after having proposed a theoretical framework for the analysis.

\section{Coordinated focal pricing - theoretical framework}

Inspired by Schelling (1963), the economic literature on focal points in problems of coordination is mainly game-theoretic. ${ }^{13}$ In the industrial organization literature, the use of focal points in tacit collusion games has been noted, see for example Scherer and Ross (1990, p. 265ff) or Ivaldi et al. (2003); but it has received little rigorous theoretical treatment. Maskin and Tirole (1988) have the notion of a focal price in a dynamic homoge-

approve certain titles for school use and are regional monopsonists. In response, the supply side is also fairly concentrated, making this particular segment a bilateral oligopoly.

${ }^{13}$ This literature introduces framing, the application of labels to strategies (Sugden, 1995). The major concern of this literature is how players use frames to achieve an efficient equilibrium of a pure coordination game, and in particular, how they choose between rival focal points (Binmore and Samuelson, 2002). See Mehta et al. (1994) for an experimental study. 
neous good duopoly setting. They define a focal price as the stable price in a Markov perfect equilibrium, in the sense that once set, firms continue to charge this price forever.

However, not only the above price distributions seem to suggest that a standard model of dynamic oligopoly may not be an appropriate framework to analyze this industry. It is also unclear conceptually, whether book markets are not better described by monopoly models which are prevalently used in the analysis of RPM. At least in the important fiction segments of the market, the degree of substitutability between different titles and so the scope for collusion - may be rather small. Even in segments where products presumably are imperfect substitutes, such as travel guides for the same destination, collusion may face sustainability problems. The number of (multi-product) firms is often large (Symeonidis, 2002), barriers to entry are low (van der Ploeg, 2004) and practicable punishment schemes are hard to imagine.

In addition, dynamic price competition does not involve flexible prices for a given title. Price changes are very rare in the book market even without RPM, as the US case shows (Clerides, 2002). Firms do compete repeatedly, but with changing titles. As a simple theoretical framework to structure the following empirical analysis, I modify an existing model of a duopoly with consumer heterogeneity in order to accommodate these and other particularities of media industries as well as the possibility of coordinated focal pricing. This framework differs from the standard approach to collusion (supergames) in a number of ways. Since it suggests that coordinated focal pricing is not necessarily bad for consumers, I do not use the term "collusion".

\subsection{Coordination in a duopoly with consumer loyalty}

Point of departure is a variation of Varian's (1980) model proposed by Deneckere et al. (1992, henceforth DKL). DKL use consumer heterogeneity to motivate price leadership. In their model, some consumers are loyal in the sense that they strictly prefer one of two differentiated products, while some are price sensitive and therefore prefer the cheaper product. ${ }^{14}$ In contrast to Varian (1980), firms have no means to price discriminate be-

\footnotetext{
${ }^{14}$ Such informational heterogeneity on the side of buyers is common in the price dispersion literature. However, this literature's focus is on spatial (Salop and Stiglitz, 1977, for example) or temporal price variations (Varian, 1980) of a homogeneous good.
} 
tween consumers. Once decided upon and communicated, prices are ex post inflexible. DKL show that with two asymmetrically popular firms, the firm with the larger group of loyal consumers endogenously becomes a price leader, determining the uniform market price.

This setup fits to some of the stylized characteristics of the book market. First, consumer heterogeneity is certainly present. Some buyers are informed and want to buy a specific title, some come undecided and want to see what a particular retailer has to offer (so-called 'impulse buyers'). Second, publishers' price decisions are usually irreversible. Publishers decide on a price before the title is introduced to the market. Adjustments seem to be infeasible during a title's primary selling season - which in practice is at most 6 months - and are rare afterwards. ${ }^{15}$

On the other hand, market structure in this industry is quite fragmented - far from a duopoly at least. Competition between available titles is limited additionally by the fact that due to specialization or restrictions in shelf space, a retailer only has a small share of all titles on stock. Presumably, every retailer's selection of stocked titles is a different one. While informed buyers will manage to get their favorite title, undecided buyers choose between titles on stock at the retailer they happen to walk in. Unlike in DKL, a publisher therefore cannot identify the specific titles that compete with his title for undecided buyers. In fact, the set of competing titles is a different one for every retailer. Simple direct price coordination, for example by means of a leader-follower scheme as in DKL, is not feasible in this case.

\subsection{Coordinated focal pricing in fragmented media markets}

Consider the following formalization. A publisher has to decide on a price $p$ for a title to be introduced to the market. She knows there are $n$ loyal consumers who will buy the title definitely, if $p$ is not larger than their reserve price $r .{ }^{16}$ Also, $m$ consumers with reserve price $r_{m}$ will be undecided between this title and a competing title $j$ : call them the

\footnotetext{
${ }^{15}$ Price increases are extremely rare, while markdowns sometimes occur after the selling season to sell off remaining inventory. Presumably, publishers who choose not to fix prices via RPM want to provide retailers with the opportunity of such remnant sales.

${ }^{16}$ Although the following reasoning will be applied to a large number of titles, title subscripts for $p, n$ and $r$ are omitted here for legibility.
} 
switchers. They will buy the cheaper of the two titles in case both are priced below $r_{m}$ and either one with $50 \%$ chance in case prices are the same. The publisher knows neither the price nor the identity of the competing title exactly. However, she knows that $p_{j}$ is distributed according to a specific c.d.f. $F($.$) such that \operatorname{Pr}\left(p_{j} \leq p\right)=F(p)$. Imagine $F($.$) as$ the distribution of prices in the relevant range $\left[0 ; r_{m}\right]$ observed in previous pricing rounds (e.g., seasons). The market has a focal price $p^{f}$ if $F($.$) has a mass point at p^{f}$. Production costs are zero. To facilitate things, normalize parameters such that $m$ and $r_{m}$ are equal to one. The interesting and realistic case is the one where the group of switchers is larger than the group of loyal consumers, hence $0<n<1$.

Hypothetical benchmark. Suppose for the moment that $F($.$) is uniform over [0 ; 1]$; thus no focal point exists. We will see below that this is an inconsistent assumption. Then, $\operatorname{Pr}\left(p_{j} \leq p\right)=p$ if $p<1$ and one else. The publisher's expected profit is

$$
E \pi_{1}^{U}(p)=\left\{\begin{array}{lll}
p(1-p+D n) & \text { if } & 0<p \leq 1 \\
D p n & \text { if } 1<p,
\end{array}\right.
$$

where $D$ is equal to one as long as $p \leq r$ and zero else.

First, consider the case $r>1$ (hence $D=1$ in the first line of equation 1 ). This is arguably the more realistic case, since you may expect loyal consumers to have a higher reserve price than switchers. If the publisher wants a share of the switchers' demand, the usual first-order condition applied to the first line of (1) yields an optimal 'competitive' price of $\frac{1+n}{2}$. The respective expected profit is $\frac{(1+n)^{2}}{4}$. However, if $r$ is high enough, it may be more profitable to extract all off this by setting $p=r>1$, leaving aside competition for the switchers. Comparing expected profits, this is the case for $r>\frac{(1+n)^{2}}{4 n}$.

In case $r<1$, two other restrictions may apply. The 'competitive' price is not feasible if $r<\frac{1+n}{2}$. The publisher then optimally sets $p=r$, since expected profit is increasing in $p$ in the respective range, and has an expected profit of $r(1-r+n)$. However, if $r$ is very low, it may be more profitable to target switchers only by pricing above $r$ (as if $n=0$ ). Then, she would set $p=\frac{1}{2}$ and expect a profit of $\frac{1}{4}$. Comparing expected profits, this is the case if $r \leq \frac{1+n}{2}-\frac{\sqrt{n(2+n)}}{2}$. Putting these results together gives the publisher's optimal price function for the case of a uniform $F(),. p^{U}$, depending on $r$ and $n$ : 


$$
p^{U}(r, n)= \begin{cases}\frac{1}{2} & \text { if } \quad r \leq \frac{1+n}{2}-\frac{\sqrt{n(2+n)}}{2} \\ r & \text { if } \quad \frac{1+n}{2}-\frac{\sqrt{n(2+n)}}{2}<r<\frac{1+n}{2} \\ \frac{1+n}{2} & \text { if } \quad \frac{1+n}{2} \leq r \leq \frac{(1+n)^{2}}{4 n} \\ r & \text { else. }\end{cases}
$$

The function $p^{U}(r, n)$ is inconsistent with the initial assumption on $F($.$) , though. If all$ firms in the market use this pricing function (with different $r_{j}$ and $n_{j}$ entering), our publisher cannot believe that $F($.$) has no focal point. In other words, a uniform F($.$) cannot be$ the outcome of previous pricing rounds in this fashion. For example, if $F($.$) is the result$ of prices of a large number of titles whose $r_{j}$ and $n_{j}$ are uniformly distributed on some interval including $[0 ; 1]$, it will have a mass point at $\frac{1}{2} \cdot{ }^{17}$ See appendix A for a simulation.

Coordinated focal pricing. How would equation 2 change if there were a focal price? Suppose the publisher believes that

$$
p_{j}\left\{\begin{array}{l}
=p^{f} \quad \text { with probability } q \quad(0<q<1) \\
\text { is uniformly distributed (as before) with probability } 1-q .
\end{array}\right.
$$

Say, $q$ is the empirical share of all titles in the relevant range $[0 ; 1]$ that were priced at $p^{f}$ in the last season. Depending on whether $p$ is higher, lower or equal to $p^{f}$, the publisher's expected profit is

$$
E \pi_{1}^{F}(p)=\left\{\begin{array}{lll}
(1-q) p(1-p+D n)+q p(1+D n) & \text { if } & p<p^{f}<1 \\
(1-q) p^{f}\left(1-p^{f}+D n\right)+q p^{f}\left(\frac{1}{2}+D n\right) & \text { if } & p=p^{f}<1 \\
(1-q) p(1-p+D n)+q p D n & \text { if } & p^{f}<p<1 \\
p D n & \text { if } \quad p^{f}<1<p .
\end{array}\right.
$$

Obviously, it is very attractive to undercut $p^{f}$ by a small amount. But then, why should a publisher expect $p^{f}$ to be a mass point of the price distribution in the first place? It

\footnotetext{
${ }^{17}$ Another puzzle appears to be that the resulting price distribution has an upper bound exceeding that of $F($.$) . More precisely, the publisher under consideration expects only competitors with prices below 1$ but allows herself to price above 1 . She can do so because titles with prices above 1 - although existent - are irrelevant for her decision. They are out of competition for the switchers' demand.
} 
is precisely for this reason that we suspect focal pricing to be a coordinated outcome. Imagine there is a coordination authority (say, a trade association) that can observe all parameter values after prices have been determined. It checks every undercutting firm $i$ for $r_{i}<p^{f}$ and is able to severely punish those who set a price such that $r_{i} \neq p_{i}<p^{f}$. Only publishers who have to undercut $p^{f}$ in order to serve their loyal consumers are allowed and able to do so. ${ }^{18}$

Even under such a coordination mechanism, there is room for title-specific optimization similar to the above benchmark case. Sorting out the publisher's price function is somewhat more involved, though, since you have to deal with two additional parameters ( $q$ and $p^{f}$ ). The specific results depending on these parameters are secondary for the purpose of this paper and therefore referred to the appendix. Here I only summarize the procedure and the resulting price function. As before, for a very low $r$ it is better to focus on switchers only. Comparing the respective expected profit for $p=r<p^{f}$ with that from focal pricing with $n=0$ gives a lower bound on $r$ depending on the other parameters, $r^{\min }\left(n, q, p^{f}\right)$. For reserve prices above $r^{\min }$ yet still below $p^{f}$, the publisher optimally sets $p=r$.

When $r>p^{f}$, the choice is between focal pricing and setting a price above $p^{f}$. Constrained maximization of the third line of the above expected profit function gives a potentially optimal price of $\bar{p}=\frac{1+n-q}{2(1-q)}$, which is feasible (lying between $p^{f}$ and one) only for intermediate $n$. It is optimal compared to focal pricing only for small $q$ and not too large $r$ (with respective bounds $n^{\min / \max }, \bar{q}$ and $\bar{r}$ dependent on $p^{f}, n$ and $q$ ). In case these conditions are met for $n$ and $q$ but $r$ lies between $p^{f}$ and $\bar{p}$, the optimal price is $p=r$ since the respective profit function is increasing in $p$. In case these conditions on $n$ and $q$ are not met, it is more profitable to set either $p=p^{f}$ or $p=r$. Comparing the respective expected profits yields an upper bound for $r$ above which the publisher leaves the competition for switchers: $r^{\max }\left(n, q, p^{f}\right)$. Assembling these results gives a publisher's price

\footnotetext{
${ }^{18}$ The purpose of this paper is not to show whether or how coordinated focal pricing could work explicitly in this setup. Given this particularly simple coordination mechanism, I only check whether the resulting price function is a consistent one and derive an estimation strategy for the empirical analysis.
} 
function under coordinated focal pricing:

$$
p^{F}\left(r, n, p^{f}, q\right)= \begin{cases}p^{f} & \text { if } r \leq r^{\text {min }} \\ r & \text { if } r^{\text {min }}<r<p^{f} \\ p^{f} & \text { if } p^{f} \leq r \leq r^{\text {max }} \text { and } \quad\left(n \leq n^{\text {min }} \text { or } q>\bar{q}\right) \\ r & \text { if } p^{f} \leq r<\bar{p}, \quad n^{\text {min }}<n \leq n^{\text {max }} \text { and } q \leq \bar{q} \\ \bar{p}=\frac{1+n-q}{2(1-q)} & \text { if } \bar{p} \leq r \leq \bar{r}, \quad n^{\text {min }}<n \leq n^{\text {max }} \text { and } q \leq \bar{q} \\ r & \text { else. }\end{cases}
$$

The precise expressions for $r^{\min }, r^{\max }, n^{\min }, n^{\max }, \bar{q}$ and $\bar{r}$ are given in appendix A. Compared to the price function for $p^{U}$, here $p^{f}$ replaces $\frac{1}{2}$ as the price to target switchers only. For a range of parameter values - i.e. the third case of equation 4 - it is profitable to do focal pricing although loyal consumers are willing to pay more. An important feature of this pricing function is the fact that the focal price contains no title-specific information (through $r$ or $n$ ), while all other prices do. This result is used as a central identification assumption in the following empirical section.

For an outsider who treats $n$ and $r$ as uniformly distributed random variables, $p^{f}$ is the only mass point in the price distribution. If all firms in the market use this pricing function (with different $r_{j}$ and $n_{j}$ entering), the initial assumption on $p^{f}$ is thus consistent. In addition, stability of $p^{F}($.$) and the corresponding coordination mechanism would re-$ quire that $q$ is a good estimate of the resulting share of focally priced titles in the relevant range. In the appendix, I assess this by simulation and find for a number of candidate focal points that there is a specific and reasonable $q$ for which $p^{F}($.$) is stable in this sense.$

How does all this affect consumers? With a simulated distribution of $\left(r_{i}, n_{i}\right)$ for 1000 titles, the average price is about 0.9 in the hypothetical benchmark case of a uniform $F($.$) , while$ it is slightly lower (0.88) if pricing is according to equation 4 with $p^{f}=\frac{1}{2}$ (see appendix). This is due to the fact that on the one hand, the coordination mechanism imposed does not deter firms from undercutting the focal price when their loyal consumers are not willing to pay $p^{f}$, while on the other hand it induces at least some firms to cut their price from $r$ down to $p^{f}$ in order to 'meet the competition' for switchers. But the simulated 
average price increases when the focal price increases. It becomes 0.9 for $p^{f}=\frac{3}{4}$ and goes up to 0.99 for the largest possible $p^{f}=1$.

Therefore, the effects of coordinated focal pricing on average prices are unclear. An increase in average prices through focal pricing - compared to the benchmark case - is dependent on the ability of publishers to coordinate on a focal price close to one. This ambiguity should be similar in markets with more than one focal price: expected average prices should depend on the focal points' level, the distance between them and the share of titles priced on these points.

\subsection{The role of RPM}

Until now, I have assumed that publishers can determine the retail price. Which is true for titles under RPM, but not for titles with flexible prices. The conjectures that RPM in general facilitates collusive pricing and that collusive pricing is often coordinated via focal points have yet received little formal foundation. This is particularly true for their combination: the relationship between RPM and tacit collusion on focal prices. In either case, progress on these grounds is beyond the scope of this paper. Let me just note, instead, that there are several reasons why publishers may not be able to control retail prices appropriately via non-linear wholesale contracts, if RPM is not an option; for instance, cost heterogeneity of retailers, transaction costs due to the large number or retailers, or laws that require equal wholesale conditions for all retailers (Kandel, 1996). The frequent use of 'Minimum Advertised Pricing' programs in music publishing is another indicator of the manufacturers' desire to control retail prices in these industries (Wang, 2004).

In addition, even homogeneous retailers selling a homogeneous good will want to introduce price dispersion when faced with informational imperfections on the side of buyers (cf. the above cited literature on price dispersion). For the book industry, a number of recent empirical studies of on- and offline book prices in the US confirm this assertion (Chevalier and Goolsbee, 2003; Clay et al., 2001, for example). If retailers not subject to RPM introduced additional price dispersion, coordination between publishers would be complicated, since the resulting price distribution may not offer clear focal points. 


\subsection{Alternative explanations}

Factors other than upstream coordination may account for the observed price distributions with perceived focal points. First of all, it may be the case that the distribution of consumers' reserve prices has mass points. If, say, $40 \%$ of all consumers loyal to distinct titles have a reserve price equal to 20 , that price will appear as focal even when the respective publishers do not consider competition for switchers in their pricing decision. Pricing patterns will then not differ empirically between titles on and off perceived focal points since in either case title-specific parameters determine a title's price.

Dominant-firm price leadership is an alternative explanation. As DKL show, a dominant firm may emerge as price leader and effectively determine a uniform market price. In the context of the book market with multi-product firms and various market segments, price leadership may consist in the determination of a set of price points. Fringe firms would follow, which in effect yields a price distribution with mass points chosen by the price leader. I assess this possibility in section 4.3.

Firms' uniform pricing policies may also lead to the observation of focal price points. Eventually, firms prefer to set a uniform price for all or a subset of their titles, for example when overhead costs are large but also for marketing-related reasons. ${ }^{19}$ In segments with some large firms, such uniform pricing will lead to mass points in the price distribution even without coordination efforts. This possibility is evaluated in section 4.3 as well.

\section{Focal pricing with optional RPM - empirical approach}

What do these theoretical considerations imply for an empirical analysis of book prices? Suppose coordinated focal pricing as characterized by equation 4 is the data-generating process for the observed distribution of prices shown in figures 1 and 2. The primary implication for an empirical analysis is that focal prices contain no title-specific information whatsoever. Conversely, non-focal prices are driven by title-specific parameters, i.e. the number of loyal consumers and their reserve price. The same reasoning applies to cost factors, which were not included in the above formalization for simplicity but most likely

\footnotetext{
${ }^{19}$ For example, travel guides appearing in a given publisher's series often have a uniform price, although production costs and possibly consumers' reserve prices differ between titles (destinations).
} 
play an important role in pricing decisions. Given title-specific data on these factors, one may estimate a hedonic pricing equation using only those titles with non-focal prices. If observed focal pricing is due to publisher coordination, predicted hedonic prices for focally priced titles should be different than actual prices. If focally priced titles are predominantly more expensive than their implied hedonic prices, such coordination can be called detrimental to consumer surplus.

Knittel and Stango (2003, henceforth KS) propose a similar identification scheme. They study collusion on focal prices - in terms of interest rates - between US credit card issuers at the state-level during the 1980s. In their study, potentially collusive focal points are directly observable in the form of state-imposed interest rate ceilings. In addition, KS have a control group of states that did not impose a ceiling. They assume a reducedform pricing equation for off-ceiling interest rates and find that a significant portion of credit card issuers set above-average prices at the ceiling. They interpret their result as an indication of tacit collusion on focal prices.

A main difference between this paper and that of KS is that it is not manifest here when a price qualifies as focal. I therefore experiment with various definitions. Another important difference to KS is the explicit consideration of the decision on RPM, which is taken jointly with that on focal pricing. The influence of hedonic prices, pricing of potential competitors as well as a number of other factors on these decisions is estimated in section 4.3.

\subsection{Hedonic non-focal prices}

Looking at actual price distributions, you have seen in section 2 that in each market segment there is potentially not one, but a set of focal prices. Suppose for the moment that this set is known for every segment. I have argued that offside focal points, observed prices depend on the number of loyal consumers, their reserve prices, and costs. Suppose that these title-specific values are functions of a title's vector of product characteristics $(x)$ and of other unobservable factors. The resulting price, denoted by $p^{*}$, is therefore 
hedonic and can be represented by the following reduced form:

$$
p^{*}=f\left(x, \beta_{k}\right)+\varepsilon .
$$

In this equation, $\beta_{k}$ is a vector of coefficients capturing segment-specific cost- and demandeffects of observable product characteristics. The error term $\varepsilon$ captures effects unobservable to the econometrician, e.g. from differences in unobserved product characteristics such as author reputation or cover design. A standard assumption is that product characteristics are exogenous to the pricing decision. I justify this assumption in more detail in section 4.4.

In principle, $f($.$) can be estimated using the observations on titles with non-focal prices.$ While using such a subsample of titles can induce selection bias in certain circumstances, it does not seem to be critical here (see section 4.4 for more detail). Unfortunately, unlike KS I have little a priori knowledge to be able to safely identify the set of focal prices within a market segment. A working definition could do the trick, however. I experiment with various definitions for focality and cross-check respective estimation results. Results are qualitatively invariant across definitions.

A focal price: working definitions. As in section 2, I partition observed prices into clusters (1-DM intervals around a whole number). Three versions of a 'rational' working definition regard the one, three or five largest price clusters per segment as focal, where size is in terms of the number of titles priced at the respective points. The definitions are labeled Top1, Top3 and Top5. ${ }^{20}$ In order to avoid mistaking as focal, say, the fourth largest yet comparatively insignificant price cluster in a segment with highly dispersed prices, a second requirement for focality is that candidate clusters have to include at least $5 \%$ of a segment's titles.

I define focal prices on the 3-digit segment level, thus for 130 segments altogether. A dummy variable $d F O C A L$ is set to one for all titles that are priced in the clusters tagged focal by the respective definition. Segments can differ in the number of focal points found. For example, consider definition Top3. When prices in a segment are highly dispersed,

\footnotetext{
${ }^{20}$ I also experimented with three analogous 'psychological' working definitions. They accept only those clusters as potentially focal, which fit to a broad version of the ' 9 fixation': those around 5, 10, 15, 20 DM and so on. However, results obtained are fairly similar to the less restrictive 'rational' definition, and are thus not reported. See section 4.4 for more detail.
} 
such that it has only one price cluster including more than $5 \%$ of its titles, only this one cluster will be tagged focal. When prices in a segment concentrate on five clusters all containing at least $5 \%$ of the titles, the three largest will be tagged focal.

Using definition Top3, the most frequent clusters found focal across segments are those around $20,15,30,17,40,25,10,13,18,50$ and 19 DM (ordered by frequency). They account for about $83 \%$ of all focal points found using this definition. Table 2 gives some cross-segment summary statistics on size, active firms and the occurrence of focal prices depending on the three definitions. Naturally, the average segment's share of titles on the focal point(s) is increasing in the number of points allowed by the definition. It more than doubles for Top3 (40\%), compared to Top1 (19\%), but increases by much less if one goes up to Top5 (49\%). Regardless of the definition, a considerable share of firms do not price focally. Note from the Min./Max. column that for every definition except Top1, there are segments without focal points (focally pricing firms), as well as segments where all titles are focally priced (all firms price focally). Table 3 gives cross-publisher summary statistics on firm size (number of titles), diversification (number of segments a publisher is active in) and focal pricing. For definition Top3, the average publisher has about $22 \%$ of its titles priced focally.

Table 2: Cross-segment summary statistics on size, active firms and focal pricing

\begin{tabular}{lccc}
\hline Variable & Mean & Std. deviation & Min. / Max. \\
\hline Segment size (No. of titles) & 1020 & 1525 & $6 / 7641$ \\
$\begin{array}{l}\text { No. of active firms in segment } \\
\text { Definition Top1: }\end{array}$ & 115 & 141 & $1 / 695$ \\
Focally priced titles (share) & 0.19 & 0.13 & $0 / 0.73$ \\
$\begin{array}{l}\text { Focally pricing firms (share) } \\
\text { Definition Top3: }\end{array}$ & 0.27 & 0.14 & $0 / 1$ \\
Focally priced titles (share) & 0.40 & 0.20 & $0 / 1$ \\
Focally pricing firms (share) & 0.46 & 0.20 & $0 / 1$ \\
$\begin{array}{l}\text { Definition Top5: } \\
\text { Focally priced titles (share) }\end{array}$ & 0.49 & 0.24 & $0 / 1$ \\
Focally pricing firms (share) & 0.55 & 0.22 & $0 / 1$ \\
\hline Observations: 130 3-digit segments. & & \\
\hline
\end{tabular}


Table 3: Cross-publisher summary statistics on size, diversification and focal pricing

\begin{tabular}{lccc}
\hline Variable & Mean & Std. deviation & Min. / Max. \\
\hline Size (titles) & 43 & 160 & $1 / 4205$ \\
No. of segments in portfolio & 5 & 7 & $1 / 77$ \\
Focally priced titles (share, def. Top3) & 0.22 & 0.30 & $0 / 1$ \\
\hline Observations: 1643 publishers. & & & \\
\hline
\end{tabular}

Estimating hedonic prices. Given a working definition of focal prices, I estimate the $\beta$ parameters of the reduced-form pricing relationship (equation 5) using the subset of titles with non-focal prices. In view of the evident differences between price distributions of hardcovers and paperbacks in popular and professional segments (cf. figures 1 and 2), this analysis is done separately for these four groups of market segments. A semi-log specification is chosen as functional form for $f($.$) , since it is standard in the estimation of$ hedonic prices: ${ }^{21}$

$$
\ln \left(p_{i j k}\right)=x_{i}^{\prime} \beta_{k}+\lambda_{k}+\kappa_{j}+\varepsilon_{i} ; \quad i=1, \ldots, N ; \quad j=1, \ldots, J ; \quad k=1, \ldots, K .
$$

Product characteristics in $x_{i}$ include title $i$ 's number of pages and dummy variables indicating the title's type of binding, whether it has black or colored images, whether it is a reprint, whether it is part of a series and the year of publication. Some interaction terms are also included. See tables 9 to 11 in the appendix for a complete list, descriptions and summary statistics of these variables. Fixed effects for $K$ market segments and J publishers are captured by $\lambda_{k}$ and $\kappa_{j}$, respectively. Regarding the error term $\varepsilon_{i}$, the standard OLS assumptions are at play. The resulting regression coefficients are of secondary interest, since their primary function is to serve as inputs in the analysis of focally priced titles. Report and discussion of estimated coefficients is therefore referred to appendix B. Table 4 gives a digest, focussing on fixed effects and fit statistics. Most notably, fit of the regression as measured by $R^{2}$ is not strictly proportional to sample size and the number of active publishers is considerably lower in paperback segments.

\footnotetext{
${ }^{21}$ In addition, fit is considerably better compared to the linear specification. In view of the large number of dummy variables in the data, a double-log specification as well as Box-Cox transformations of the variables did not seem appropriate.
} 
Table 4: Hedonic regression results: digest

\begin{tabular}{lcccc}
\hline \multicolumn{5}{c}{ Dependent variable: $\ln ($ price) } \\
Segment: & $\begin{array}{c}\text { Popular } \\
\text { hardcover }\end{array}$ & $\begin{array}{c}\text { Popular } \\
\text { paperback }\end{array}$ & $\begin{array}{c}\text { Professional } \\
\text { hardcover }\end{array}$ & $\begin{array}{c}\text { Professional } \\
\text { paperback }\end{array}$ \\
\hline Coefficient estimates: reported in table 12 (appendix). \\
Fixed effects (number): & & & & \\
Binding dummies & 21 & 21 & 21 & 21 \\
Years of publication & 3 & 3 & 3 & 3 \\
2-digit segments & 32 & 31 & 37 & 32 \\
Publishers & 1196 & 189 & 1316 & 192 \\
\hline Observations & 23312 & 6025 & 48609 & 3641 \\
$R^{2}$ & 0.73 & 0.65 & 0.75 & 0.81 \\
Adjusted $R^{2}$ & 0.71 & 0.64 & 0.74 & 0.79 \\
\hline \multicolumn{5}{l}{ Note: Based on OLS estimation results for focal price definition Top3. } \\
\hline \multicolumn{5}{l}{}
\end{tabular}

\subsection{Are fixed focal prices fair?}

Estimates obtained for the coefficients in equation 6 are used to predict hedonic prices for all titles in the sample. ${ }^{22}$ In order to answer the question whether fixed focal prices are bad for consumers ('unfair'), I compare actual $(p)$ and predicted hedonic prices $\left(\hat{p}^{*}\right)$ for focally priced RPM and non-RPM titles. To facilitate comparison and interpretation, I analyze the log difference $p$ Diff: $\ln (p)-\ln \left(\hat{p}^{*}\right)$. For non-focally priced titles, $p$ Diff is just the regression residual $\hat{\varepsilon}$, which by construction should be zero on average. Not so for focally priced titles, which were not included in the above estimation. If focal pricing is a coordination device to implement above-hedonic prices, the prediction error $p$ Diff should be positive for these titles: a measure for the sustained 'focality markup'. The four panels in figure 3 compare the distribution of the regression residuals (kernel density, dashed line) with the distribution of the prediction error for focally priced titles (histogram). ${ }^{23}$

Except for the group of popular paperback segments, the average prediction error for focally priced titles (indicated by a solid vertical line) is negative. In the exceptional group, it is very close to zero. Nevertheless, there seems to be some evidence of opportunistic focal pricing. In popular paperback segments, for example, we find density peaks at 'fo-

\footnotetext{
${ }^{22}$ For a fairly small number of titles (between 53 and 215 depending on the group of segments), this is not feasible because their publishers priced all their titles focally (cf. table 3). I cannot estimate the fixed effect $\left(\kappa_{j}\right)$ for these publishers and hence cannot predict hedonic prices for their titles.

${ }^{23}$ Binwidth is 0.01 , corresponding to a $1 \%$-difference between $p_{i}$ and $\hat{p}^{*}$.
} 
Figure 3: Projected differences from the hedonic price
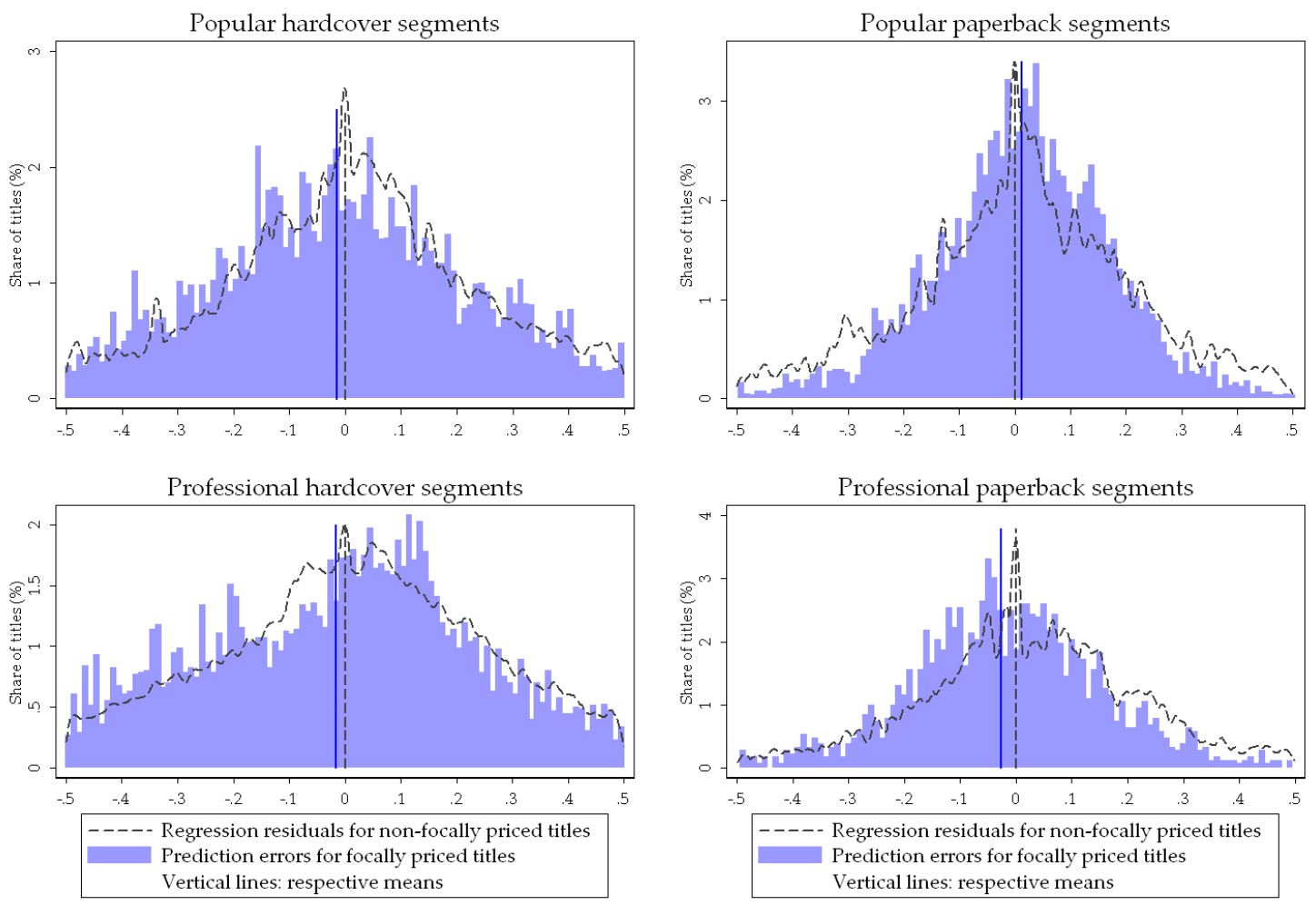

cality markups' around 5 and 10\% over the predicted hedonic price. However, 'focality markdowns' can be found similarly (LHS of the distribution). As reflected by negative means, they seem to dominate in mass for three of the four groups. Figure 3 cannot completely answer the question whether fixed focal prices are fair, though, since it does not distinguish between titles with fixed and flexible prices. This is done in table 5, which gives mean and standard deviation of $p$ Diff both for focally and non-focally priced RPM and non-RPM titles.

Focally priced RPM titles most often have lower prices than expected from the hedonic regression results. Only for popular paperback RPM titles, the average 'focality markup' is significantly positive but small (below 1\%). Although non-RPM titles are on average cheaper than RPM titles off focal points, on focal points they have significantly higher than projected prices in two groups. Only in the group of popular hardcovers, they show the same significant 'focality markdown' pattern than RPM titles.

Interim conclusion. Figure 3 and table 5 suggest that, if focal pricing is a coordination device at all, it coordinates competition rather than collusion: on average, the consumer 
Table 5: Differences between predicted and actual price

\begin{tabular}{|c|c|c|c|c|}
\hline & \multicolumn{2}{|c|}{ Popular hardcover } & \multicolumn{2}{|c|}{ Popular paperback } \\
\hline & $d R P M=0$ & $d R P M=1$ & $d R P M=0$ & $d R P M=1$ \\
\hline $\begin{array}{l}d F O C A L=0 \\
\text { Mean }\end{array}$ & -0.040 & $(0.003)$ & $(-0.003)$ & $(0.000)$ \\
\hline Std. deviation & 0.373 & 0.352 & 0.305 & 0.259 \\
\hline $\begin{array}{l}\text { Frequency } \\
d F O C A L=1\end{array}$ & 1,696 & 21,610 & 163 & 5,865 \\
\hline Mean & -0.070 & -0.011 & 0.163 & 0.008 \\
\hline Std. deviation & 0.365 & 0.325 & 0.282 & 0.184 \\
\hline \multirow[t]{2}{*}{ Frequency } & 854 & 12,194 & 126 & 6,944 \\
\hline & \multicolumn{2}{|c|}{ Professional hardcover } & \multicolumn{2}{|c|}{ Professional paperback } \\
\hline$d F O C A L=0$ & $d R P M=0$ & $d R P M=1$ & $d R P M=0$ & $d R P M=1$ \\
\hline Mean & -0.018 & $(0.003)$ & $(-0.039)$ & $(0.001)$ \\
\hline Std. deviation & 0.297 & 0.400 & 0.311 & 0.292 \\
\hline $\begin{array}{l}\text { Frequency } \\
d F O C A L=1\end{array}$ & 7,009 & 41,598 & 80 & 3,561 \\
\hline Mean & 0.028 & -0.022 & $(-0.085)$ & -0.027 \\
\hline Std. deviation & 0.296 & 0.351 & 0.449 & 0.216 \\
\hline Frequency & 1,094 & 7,391 & 12 & 1,998 \\
\hline \multicolumn{5}{|c|}{$\begin{array}{l}\text { Note: Group-wise means, standard deviation and frequency for } \\
p D i f f=\ln (p)-\ln \left(\hat{p}^{*}\right) . d R P M=1 \text { denotes titles sold under RPM, } \\
d F O C A L=1 \text { denotes titles sold at a focal price (definition Top3). } \\
\text { Means in brackets are not significantly different from } \\
\text { zero ( } 5 \% \text {-level, t-test). }\end{array}$} \\
\hline
\end{tabular}

surplus effect of focal pricing under RPM seems to be negligible, if not positive. Yet, there is an important caveat. This conclusion stems from an analysis which gives equal weight to every title in the sample. The data at hand do not include sold quantities, which would be needed as proper weights to determine 'real' average prices.

While this straightforward analysis of price differences is nevertheless informative concerning the effects of focal pricing with optional RPM, it is not very helpful for understanding the phenomenon. An attempt in that direction is presented in the following section. For a number of reasons, this analysis concentrates on the two groups of popular segments. First, the rationale for focal pricing presented in section 3 is fitted to retailoriented mass market segments. It seems less reasonable for titles targeted to specialized readerships like scientific publications, let alone the exceptional schoolbook market. Furthermore, any estimation method applied to these segments would have to rely on a very low number of focally priced non-RPM titles (12, cf. table 5) in the group of professional paperback segments. 


\subsection{Determinants of focal pricing under optional RPM}

In order to assess some explanations for observed focal pricing as well as a potential interdependence with the RPM decision, one might think of a simultaneous latent variable model such as the following:

$$
\begin{aligned}
& y_{F}^{*}=\delta_{F} d R P M+\gamma_{F} x_{F}+v_{F}, \\
& y_{R}^{*}=\delta_{R} d F O C A L+\gamma_{R} x_{R}+v_{R},
\end{aligned}
$$

where $v_{F}$ and $v_{R}$ are error terms with $\operatorname{Cov}\left[v_{F}, v_{R}\right]=\rho . y_{F}^{*}$ and $y_{R}^{*}$ represent the unobserved benefits from focal pricing and RPM, respectively. The vectors $x_{F}$ and $x_{R}$ contain independent variables influencing these benefits. Observed decision outcomes are binary:

$$
\begin{aligned}
& d F O C A L=\mathbb{1}\left(y_{F}^{*} \geq 0\right), \\
& d R P M=\mathbb{1}\left(y_{R}^{*} \geq 0\right) .
\end{aligned}
$$

This model seems to allow for an effect of RPM on the benefit of focal pricing and vice versa, measured by the $\delta$ - parameters. However, it is logically inconsistent unless $\delta_{F}$ or $\delta_{R}$ is restricted to zero (Heckman, 1978). Intuitively, when both of two binary outcome variables enter each other's latent variable equation, a truly simultaneous decision is impossible: the outcome of one decision is a precondition for the other. One of the two decisions has to be taken first - with the respective $\delta$ equal to zero - potentially correlated with the second only via the errors $(\rho)$.

With one of the $\delta$-parameters restricted to zero, equations $7 \mathrm{a}$ and $7 \mathrm{~b}$ become a recursive simultaneous-equations model as discussed, for example, by Maddala (1983) and Wooldridge (2002). Under the assumption that $v_{F}$ and $v_{R}$ follow a bivariate standard normal distribution (with $\rho \in\{-1,1\}$ ), this model can be estimated by maximum likelihood. ${ }^{24}$ Due to its binary nature, the endogeneity of the RHS dummy variable does not need special treatment: in estimation the model is equivalent to a seemingly unrelated bivariate probit (Greene, 2003). For identification of parameters it is sufficient - though not

\footnotetext{
${ }^{24}$ For applications see Holly et al. (1998) or Evans and Schwab (1995).
} 
necessary (Wilde, 2000) - that $x_{R}$ includes at least one variable not included in $x_{F}$. A Wald test of $H_{0}: \rho=0$ is an appropriate test for endogeneity, e.g. of $d R P M$ in equation 7a for the case $\delta_{R}=0$ (Fabbri et al., 2004). Before I compare results for the two zero-restrictions on $\delta$, let me introduce the independent variables.

Independent variables: FOCAL equation. The publisher's decision to deviate from the hedonic to a focal price may be dependent on the distance between these price points ( $p$ Diff). In order to distinguish the effects of 'focality markups' from those of 'focality markdowns', I separate $p$ Diff into two variables: $p$ DistNeg is the absolute value of $p$ Diff if $p$ Diff is negative ('focality markdowns'), and zero else; $p$ DistPos is the absolute value of $p$ Diff given it is positive, and zero else. Hence, if $p$ DistNeg $>0$, then $p$ DistPos $=0$ (and vice versa). If focal pricing is an instrument to implement above-hedonic prices, we expect a title's probability to be priced focally, $\operatorname{Pr}(d F O C A L=1)$, to increase in $p D i s t \operatorname{Pos}$. On the other hand, if focal pricing is 'competitive', we expect $\operatorname{Pr}(d F O C A L=1)$ to increase in $p D i s t N e g$. If the effect of $p$ Diff on $\operatorname{Pr}(d F O C A L=1)$ is just one-way no matter whether $p D$ iff is positive or negative, the coefficients for $p$ DistNeg and $p$ DistPos should have opposite signs.

As discussed in section 3.4, observed focal pricing may be a result rather of firms' uniform pricing policies instead of coordination. The following two variables allow to disentangle these effects. Denote by $p_{i}^{c}$ title $i^{\prime}$ s price cluster, by $n_{j}$ the size (number of titles) of publisher $j$ and by $n_{j}^{p_{i}^{c}}$ the number of $j^{\prime}$ s titles priced in this cluster. ${ }^{25}$ The title-specific value of FipCatShare is then the firm's share of titles priced on title i's price cluster: $\frac{n_{j}^{p_{i}^{c}}}{n_{j}}$. For example, consider a firm that publishes 10 titles, eventually in different segments, 6 of which at a price of $20 \mathrm{DM}$, three at $22 \mathrm{DM}$ and one at $23 \mathrm{DM}$. For the titles priced at 20 DM, FipCatShare takes the value 0.6 , and 0.3 or 0.1 for the other titles. If observed focal pricing is caused by uniform pricing policies, $\operatorname{Pr}(d R P M=1)$ should increase in FipCatShare. Further, denote by $n_{-j}^{p_{i}^{c}}$ the number of titles by publisher $j$ 's competitors priced on cluster $p_{i}^{c}$, by $n_{k}$ the size (number of titles) of segment $k$ and by $n_{j}^{k}$ the number of titles offered in $k$ by publisher $j$. Then, the title-specific value of CompCatShare is the share of publisher $j$ 's competitors' titles that are priced on title $i$ 's price cluster: $\frac{n_{-j}^{p_{i}^{c}}}{n_{k}-n_{j}^{k}}$. In the above example, suppose the segment of the title with price 23 DM contains 20 titles altogether, of which

\footnotetext{
${ }^{25} \mathrm{As}$ in the previous sections, I form clusters by division of observed prices into 1-DM-intervals around whole numbers.
} 
16 are published by other firms and 5 of these 16 have a price of $23 \mathrm{DM}$. For the one title published by our example firm at a price of $23 \mathrm{DM}$, CompCatShare then takes on the value .25 (4 over 16$)$.

If $\operatorname{Pr}(d F O C A L=1)$ increases in CompCatShare, then observed focal pricing is a result of publisher coordination: the presence of many competitors' titles on a focal price attracts others. Both FipCatShare and CompCatShare are scaled on 0/1, so calculating marginal effects, we can also assess which effect is more important in determining focal prices. If $\operatorname{Pr}(d F O C A L=1)$ increases in FipCatShare more strongly than in CompCatShare, then uniform pricing policies are more important in explaining focal points in the price distribution.

Finally, in segments found to be dominated by a firm at least twice as large as the secondlargest firm, a dummy $d D o m F i$ indicates titles published by the largest firm, while $d F r i n g e F i$ indicates titles by all other firms in the respective segment. ${ }^{26}$ If observed focal pricing is the result of price leadership of dominant firms, this should be reflected in a positive effect of these variables on the probability of focal pricing.

Independent variables: RPM equation. The distance between a title's hedonic and its actual list price should also influence the publisher's decision on RPM. If RPM is implemented to prohibit retailers from realizing markups or markdowns over the list price, these variables should have the respective (opposing) effects on $\operatorname{Pr}(d R P M=1)$. Given retailers have incentives to deviate from the list price towards the hedonic price, in either case these incentives - and hence the publisher's interest in fixing the price - should increase in the distance between hedonic and list price ( $p$ DistNeg/pDistPos).

Demand uncertainty is a central feature in a number of efficiency-oriented RPM theories. Attempting to assess the influence of risk and demand uncertainty on the decision on RPM, I include the size of a title's publisher (PubSize) and a title's segment (SgtSize) both in logs of the number of titles - as well as a dummy indicating whether the title is published within a series (dSeries). Titles published by larger firms (in larger segments) should be less (more) prone to risk than from smaller publishers (in smaller segments) due to stronger marketing/financial potential (less visibility). If demand uncertainty is

\footnotetext{
${ }^{26} 29$ out of 130 3-digit segments where found to be dominated according to this criterion. See section 4.4 for a discussion of results using an alternative dominance criterion.
} 
important in explaining RPM, $\operatorname{Pr}(d R P M=1)$ should thus decrease in PubSize and increase in SgtSize. Note, however, that this assertion holds for PubSize only as far as the number of titles is a good proxy for a publisher's financial potential. Demand for titles published within a series should be less variant and more predictable, so the effect of $d$ Series on $\operatorname{Pr}(d R P M=1)$ should be negative, if demand uncertainty plays a role. These measures of demand uncertainty are of limited adequacy, however, since more important quantity aspects of demand uncertainty like print size cannot be controlled for with this data.

Restriction on $\delta$ and estimation results. In order to determine whether one of the two $\delta$ coefficients can be safely restricted to zero, I compare estimation results for both logically consistent versions of model 7. In the first version, the restriction is $\delta_{F}=0$, in the second it is $\delta_{R}=0$. Although these two versions are non-nested, an encompassing approach offers a clear decision for the two groups of popular segments studied here. Table 6 gives the estimates for $\delta$ and $\rho$ as well as log-likelihood values for the two versions.

Under both versions, only for popular hardcovers the hypothesis that $d R P M / d F O C A L$ is exogenous in equation $7 \mathrm{a} / 7 \mathrm{~b}$ is rejected by a Wald test of $H_{0}: \rho=0 . \hat{\delta}_{R}$, estimated under the restriction $\delta_{F}=0$, is rather close to and not significantly different from zero for both segment groups. ${ }^{27}$ On the other hand, $\hat{\delta}_{F}$, estimated under the restriction $\delta_{R}=0$, is significantly different from zero in the joint estimation for popular hardcovers. It is not significant for popular paperbacks. For $\delta_{R}=0$ and both groups of segments, the value of the log-likelihood increases in joint estimation compared to separate probit estimations. Under $\delta_{F}=0$, the log-likelihood barely improves with joint estimation for popular paperbacks. For popular hardcovers, separate probit estimations under $\delta_{R}=0$ yield a higher $\log$-likelihood value than joint estimation under $\delta_{F}=0$.

Hence, while results obtained imposing $\delta_{R}=0$ encompass results obtained imposing $\delta_{F}=0$, this is not true the other way around. In order to analyze the joint decision on focality and $\mathrm{RPM}$ in this context, it is therefore appropriate to restrict $\delta_{R}$ to zero. As a first result, this implies that we can think of the decision on RPM as taken before the decision on focal pricing with the latter having no direct impact on the first. In the case of popular paperback segments, we additionally cannot reject the hypothesis that $\rho=0$, which implies that

\footnotetext{
${ }^{27}$ The same result is obtained in separate estimations of the two equations and even when standard errors are not corrected for presumable within-publisher correlation of errors (not reported).
} 
Table 6: Model comparison

\begin{tabular}{|c|c|c|c|c|}
\hline & \multicolumn{2}{|c|}{ Popular hardcovers } & \multicolumn{2}{|c|}{ Popular paperbacks } \\
\hline & Coefficient & (p-value) & Coefficient & (p-value) \\
\hline \multicolumn{5}{|l|}{ Restriction: $\delta_{F}=0$} \\
\hline$\hat{\delta}_{R}$ & -0.0641 & $(0.3709)$ & 0.0305 & $(0.8447)$ \\
\hline$\hat{\rho}$ & 0.2894 & $(0.0003)$ & 0.0221 & $(0.8307)$ \\
\hline Log-L, bivariate probit: & \multicolumn{2}{|c|}{-13153.97} & \multicolumn{2}{|c|}{-3021.25} \\
\hline Log-L, single equations probit: & \multicolumn{2}{|c|}{-13191.01} & \multicolumn{2}{|c|}{-3021.32} \\
\hline Restriction: $\delta_{R}=0$ & & & & \\
\hline$\hat{\delta}_{F}$ & 1.4461 & $(0.0004)$ & -0.2328 & $(0.6844)$ \\
\hline$\hat{\rho}$ & -0.4726 & $(0.0456)$ & 0.0982 & $(0.3207)$ \\
\hline Log-L, bivariate probit: & \multicolumn{2}{|c|}{-13136.80} & \multicolumn{2}{|c|}{-3020.59} \\
\hline Log-L, single equations probit: & \multicolumn{2}{|c|}{-13152.88} & \multicolumn{2}{|c|}{-3021.36} \\
\hline
\end{tabular}

Note: p-values robust to within-cluster (publisher) correlation. Those reported for $\hat{\rho}$ are those calculated from standard errors of $\operatorname{atanh} \rho=\frac{1}{2} \ln \left(\frac{1+\rho}{1-\rho}\right)$, which instead of $\rho$ is directly estimable.

$d R P M$ is exogenous in equation $7 \mathrm{a}$. The two equations can be estimated separately in this case.

As a final remark on table 6, note a potential compensating effect between the estimated signs of $\rho$ and the respective $\delta$-coefficient, e.g. comparing the two groups of segments for $\delta_{R}=0$. The estimated sign for $\delta_{F}$ only indicates the direction of the direct effect of RPM on $\operatorname{Pr}(d F O C A L=1)$. As long as the estimated $\rho$ has the opposite sign, the direction of the overall effect is not obvious from these coefficient estimates and one has to resort to marginal effects. This property of the model to frequently yield estimates for $\delta$ and $\rho$ with switched signs was also found in Monte Carlo studies by Fabbri et al. (2004).

Table 7 reports the coefficients estimated under $\delta_{R}=0$, in the case of popular paperbacks with the additional restriction $\rho=0$. Regarding the independent variables in the FOCAL equation, the estimates for $p$ DistNeg and $p$ DistPos reflect our findings from the previous section. In both groups, the direct effect of $p$ Diff on $\operatorname{Pr}(d F O C A L=1)$ seems to be positive not only for titles with positive 'focality markups' ( $p$ DistPos), but also for titles with below-hedonic prices. However, this effect is significant only with popular paperbacks for $p$ DistPos. This suggests that in paperback segments, focal pricing is an instrument rather to implement above- than below-hedonic prices. 
Table 7: Coefficient estimates

\begin{tabular}{|c|c|c|c|c|}
\hline & \multicolumn{2}{|c|}{ Popular hardcovers } & \multicolumn{2}{|c|}{ Popular paperbacks } \\
\hline & Coefficient & Std. error & Coefficient & Std. error \\
\hline $\begin{array}{l}\text { FOCAL equation (7a): } \\
d R P M\end{array}$ & $1.4461^{*}$ & $(0.4057)$ & -0.0709 & $(0.4992)$ \\
\hline pDistNeg & 0.1263 & $(0.1782)$ & 0.1370 & $(0.3822)$ \\
\hline pDistPos & 0.3554 & $(0.3827)$ & $1.2790^{*}$ & $(0.4835)$ \\
\hline FipCatShare & $2.5412^{*}$ & $(0.4234)$ & $4.0679^{*}$ & $(0.8607)$ \\
\hline CompCatShare & $60.6929^{*}$ & $(9.6807)$ & $37.9430^{*}$ & $(7.8872)$ \\
\hline$d D o m F i$ & $1.3235^{*}$ & $(0.4318)$ & $3.1228^{*}$ & $(0.6258)$ \\
\hline dFringeFi & 0.1379 & $(0.1491)$ & 0.1974 & $(0.2523)$ \\
\hline Constant & $-6.5307^{*}$ & $(0.5290)$ & $-4.0653^{*}$ & $(0.8837)$ \\
\hline $\begin{array}{l}\text { RPM equation }(7 b) \text { : } \\
\text { dSeries }\end{array}$ & -0.1454 & $(0.1032)$ & 0.6531 & $(0.4247)$ \\
\hline pDistNeg & $-0.5238^{*}$ & $(0.1246)$ & 0.2242 & $(0.4372)$ \\
\hline pDistPos & -0.2061 & $(0.1323)$ & -0.5949 & $(0.3599)$ \\
\hline SgtSize & $0.1121^{*}$ & $(0.0472)$ & $0.3253^{*}$ & $(0.1072)$ \\
\hline PubSize & $0.2296^{*}$ & $(0.0442)$ & $0.4717^{*}$ & (0.0658) \\
\hline Constant & -0.3042 & $(0.3363)$ & $-3.1290^{*}$ & (1.0030) \\
\hline$\hat{\rho}$ & -0.4726 & & 0 & \\
\hline Log-likelihood & -13136.80 & & -3021.36 & \\
\hline Observations & 36352 & & 13098 & \\
\hline No. of publishers & 1195 & & 190 & \\
\hline
\end{tabular}

The coefficients estimated for FipCatShare and CompCatShare are highly significant in both groups and therefore confirm both the uniform pricing as well as the coordination hypothesis. A look at marginal effects (given below) will provide insights as to whether one of these effects is quantitatively more important. The dominant firm hypothesis also seems acceptable at first sight: the respective dummies $d D o m F i$ and $d F r i n g e F i$ both have positive coefficients. However, if uniform pricing policies are frequently implemented by large (dominant) firms, the estimate for $d D o m F i$ might pick up some of these effects at the cost of the estimate for FipCatShare. In addition the estimate for AFringeFi is insignificant, although theory expects fringe firms to follow the dominant firm's pricing decision. Therefore, these results on dominant firm pricing should be interpreted with caution.

The implications of the RPM equation estimates are not that clear. The estimated coefficients for dSeries are insignificant and switch sign across groups. So does the estimate for $p$ DistNeg. The negative estimates for $p$ DistPos suggest that publishers do not use RPM to sustain above-hedonic prices. Consistently across groups, $\operatorname{Pr}(d R P M=1)$ is estimated 
to increase in segment size, a finding which seems to confirm the demand uncertainty hypothesis. However, if our measure of firm size (PubSize) is adequate, this conclusion has to be qualified since the estimated direction of its effect is contrary to respective expectations.

Marginal effects. Given the above coefficients, the variables' marginal effects on the outcome probabilities can be calculated, in principle for each of the four possible combinations of $d F O C A L$ and $d R P M$. I concentrate on

$\operatorname{Pr}(d F O C A L=1)=\operatorname{Pr}(d F O C A L=1, d R P M=1)+\operatorname{Pr}(d F O C A L=1, d R P M=0)$.

Marginal effects on $\operatorname{Pr}(d F O C A L=1)$ for variables which only enter the FOCAL equation are calculated in the standard way. The marginal effect of $d R P M$ on $\operatorname{Pr}(d F O C A L=1)$ is

$\frac{\mathrm{d} d \operatorname{Pr}(d F O C A L=1)}{\mathrm{d} d R P M}=\frac{\operatorname{Pr}(d F O C A L=1 \mid d R P M=1)}{\operatorname{Pr}(d R P M=1)}-\frac{\operatorname{Pr}(d F O C A L=1 \mid d R P M=0)}{\operatorname{Pr}(d R P M=0)}$.

The main interest in this number is not only whether it is positive or negative, but also whether it is larger for titles with markups over the hedonic price than for titles with markdowns. This marginal effect is therefore calculated both for a title with $p$ DistPos $>0$ and for a title with $p$ DistNeg $>0$, while all other variables are evaluated at their means. See table 8 for the results.

Table 8: Marginal effects on $\operatorname{Pr}(d F O C A L=1)$

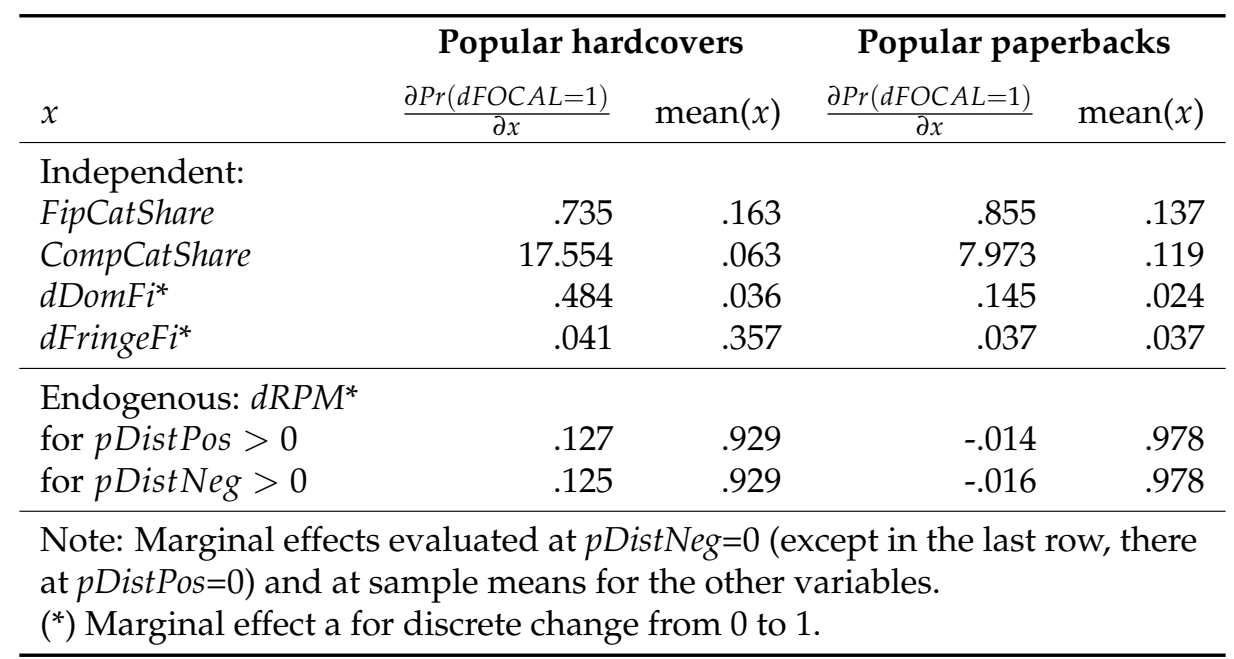

Comparing marginal effects for FipCatShare and CompCatShare, we find that focal pricing is largely due to cross-publisher coordination instead of within-firm uniform pricing policies. The probability of an average popular hardcover title to be priced focally in- 
creases by more than $17 \%$-points (nearly $8 \%$-points for a popular paperback), if the share of competitors' titles on the candidate focal point rises by 1\%-point away from the mean. The probability effect of the within-firm share of titles at the candidate focal point (FipCatShare) on this probability is much smaller: around 0.7 and $0.9 \%$-points. Popular hardcover titles published by a dominant firm are estimated to have a $48.4 \%$-points higher probability of focal pricing (14.5\%-points for popular paperbacks). However, the presence of such a dominant firm has little effect on focal pricing by the other (fringe) firms in the segment.

The marginal effect of RPM on focal pricing seems to be positive for popular hardcovers and negative yet close to zero for popular paperbacks. The probability of focal pricing increases by about 13\%-points for popular hardcover titles under RPM, compared to nonRPM titles $(d R P M=0)$. Compared to titles with 'focality markdowns' ( $p$ DistNeg $>0)$, the marginal effect hardly differs for titles with 'focality markups' ( $p$ DistPos $>0$ ). Publishers do not seem to implement RPM in order to sustain above-average focal prices in particular, although RPM and focal pricing are positively correlated in the case of popular hardcovers. This finding mirrors the results obtained in the previous section according to which in most segments, RPM titles on focal points are not priced significantly above their predicted hedonic prices. In popular paperback segments - the only group where I found focally priced titles to have a slightly positive estimated 'focality markup' on average - RPM has a negative effect on the probability of focal pricing.

\subsection{Robustness}

In this section, I discuss some critical assumptions inherent to my empirical approach. I also report findings from various alternative variable definitions and econometric specifications that were employed to examine the robustness of my results.

Exogeneity of product characteristics. A standard assumption is that product characteristics are exogenous to the pricing decision, i.e. decided upon in a preceding stage (Feenstra and Levinsohn, 1995, for example). This assumption does not seem critical in the case of books, since the author probably has a stronger authority on a title's characteristics (such as the number of pages or the inclusion of images) compared to the publisher, 
while the latter has authority with respect to pricing. Nevertheless, one may imagine a situation where, for example, publishers influence product characteristics in order to be able to price focally; or where, for some reason, titles with colored images are much more inclined to be priced focally. In consequence, hedonic regression results would carry an endogeneity bias.

In order to assess whether this is a probable scenario in the present context, a comparison of the distribution of the variables in question for focally and non-focally priced titles can be informative. Tables 10 and 11 in the appendix provide summary statistics, separately by 1-digit segment. The variables' means differ somewhat between focally and non-focally priced titles in a number of cases; yet, for all variables except one there is no evident pattern. An apparent observation, however, is that in all segments, focally priced titles have a - sometimes considerably - lower mean and variance of the number of pages. Above all, this reflects the fact that most focal prices lie at the lower end ( $<50 \mathrm{DM})$ of a price distribution which goes well into triple-digit prices at the upper end. However, the differences between focally and non-focally priced titles are slightest in those segments which exhibit the most apparent focal points: Kids/Youth and Travel paperbacks. I conclude that the assumption of exogenous product characteristics in the pricing decision is not evidently violated.

No selection bias in hedonic regression. My empirical approach implicitly assumes that excluding the focally priced titles from the hedonic regression does not trigger selection bias. Selection bias is present when the errors in equations 6 and $7 \mathrm{a}$ are correlated; that is, when there exists some correlation between the focal pricing decision and the hedonic price function which is not accounted for by the variables in the model. For example, suppose that titles by unknown authors are for some reason predominantly priced on focal points. These titles presumably have a below-average hedonic price - an effect which is unobserved to the econometrician and thus enters the error term in the hedonic estimation. The correlation between the errors in the two equations is then negative: a higher probability of focal pricing implies a lower hedonic price. Ignoring this correlation would give upward-biased predictions of hedonic prices for focally-priced titles. Hence, the predicted difference between a title's actual focal and its hedonic price - the 'focality markup' - would be too low. 
In order to test for selection bias in my results, I performed the so-called Heckit two-step estimation of equations 6 and 7a (Heckman, 1979; Wooldridge, 2002). ${ }^{28}$ The hypothesis of no selection bias in results from an independent hedonic regression cannot be rejected in the case of popular hardcover and professional paperback segments. The estimated selection bias in the other two segment groups is significantly different from - but rather close to - zero. In all cases, results regarding the level effects of focal pricing as well as estimated coefficients for equation 7a do not change qualitatively compared to the results reported here. ${ }^{29}$

Alternative focality definition. A 'psychological' definition of focal points was already mentioned. It did not lead to different estimates in the hedonic price regression. By definition, the number of focally priced titles is considerably lower according to this approach, since the prime criterion here is not only frequency but also '9 fixation'. Unfortunately, the MLE for the bivariate probit model did not converge for all groups and versions (out of Top1, Top3 and Top5) of this definition of focality. Wherever obtained, exogeneity of $d R P M$ in the FOCAL equation could not be rejected, though. Estimates from single-equation probits were qualitatively similar to those resulting from the respective 'rational' focality definition. These findings may indicate the overall inappropriateness of this 'psychological' definition of focality. In case this definition has some bite, they at least do not disqualify results obtained using the less restrictive 'rational' approach.

Alternative econometric specifications. In comparison to standard studies of hedonic pricing, fit in the hedonic regressions as measured by $R^{2}$ seems to suggest that there is room for improvement. However, an enlarged specification of the pricing equation, including more interaction terms and more detailed segment effects, did neither improve fit considerably, nor did it change the qualitative findings in consequent analyses.

Table 13 in appendix $C$ gives coefficient estimates for a bivariate probit model with additional restrictions on the FOCAL equation. In particular, the coefficients for $p$ DistNeg and pDistPos, which were mostly insignificant in the unrestricted version, were restricted to zero; analogously those for the questionable dominant-firm indicators. This allows for an

\footnotetext{
${ }^{28}$ The estimations were slightly modified in order to allow for an unrestricted estimation of the selection bias: instead of the variables $p$ DistPos/pDistNeg, all exogenous variables from the hedonic regression were included in equation $7 \mathrm{a}$. Since equation $7 \mathrm{~b}$ was not included, the potential endogeneity of RPM is ignored by this procedure.

${ }^{29}$ Results are made available upon request.
} 
assessment of the robustness of estimates for $p$ DistNeg and $p$ DistPos in the RPM equation, as well as the two variables found to be most important in explaining focal pricing: FipcatShare and CompcatShare. They are fairly robust: all estimates are very similar to those obtained for the unrestricted model, including $\hat{\rho}$. Table 14 in appendix $C$ gives coefficient estimates for a bivariate probit model with additional restrictions on the RPM equation; here, the coefficients for $p$ DistNeg and $p$ DistPos are restricted to zero. Again, all remaining parameters are very similar to their estimates from the unrestricted model.

Alternative dominance criterion. The dominance criterion implemented above - for which a firm is dominant if its market share as measured by the number of titles is twice as large as that of the market's second-largest firm - may not be accurate. For another popular criterion of dominance according to which a firm with a market share exceeding $40 \%$ is dominant, I find such dominant firms in 14 out of 1303 -digit segments (compared to 29 for the above criterion). Estimates do not change qualitatively with this alternative dominance criterion.

\section{Conclusion}

Highly differentiated media products like books or music recordings are frequently priced at apparent focal points. Among the explanations for this phenomenon is the hypothesis that manufacturers use focal pricing as an instrument of coordination, and that vertical restraints such as RPM or minimum advertised prices play a facilitating role in this game. In this paper, I propose a formal rationale for focal pricing in media industries and use a comprehensive cross-section of title-specific data on the German book market in order to assess these hypotheses empirically.

First of all, I find considerable differences in pricing between hardcover and paperback segments. This confirms a recent merger decision by the German Federal Cartel Office, which emphasized that paperback and hardcover segments constitute distinct markets (merger case Random House/Heyne). It prohibited a proposed merger that would have increased market concentration in the popular paperback segment substantially. 
A comparison of predicted hedonic prices for focally and non-focally priced titles suggests that focal pricing coordinates competition rather than collusion. Titles with focal prices are on average cheaper than their predicted hedonic price. While this also holds for titles sold under RPM, it does not always for titles with flexible prices. Results from a simultaneous probit model suggest that focal pricing is nevertheless due to upstream coordination rather than uniform pricing policies. A title's probability to be priced focally reacts much more strongly to the presence of potential competitors at a given price than to within-firm prices.

RPM titles are more probable to be priced on a focal point only where this leads to belowhedonic prices on average. For popular paperback segments, of which some appear to have most blatant focal points in their distribution of prices, I cannot reject the hypothesis that the decisions on RPM and focal pricing are independent. Altogether, these results suggest that publishers do not implement RPM in order to facilitate coordination on above-hedonic focal prices.

Despite some significant results, any approach relying on cross-section data such as that used here is limited in its ability to evaluate the welfare effects of RPM for books. Effects on product variety and sold copies are critical in this evaluation and can only be studied with quantity data. Fortunately, richer data collected from retailers' scanner cashiers is increasingly available, enabling further research into these questions. 


\section{References}

Binmore, Ken and Larry Samuelson (2002), The evolution of focal points, mimeo.

Bittlingmayer, George (1992), The elasticity of demand for books, resale price maintenance and the Lerner index, Journal of Institutional and Theoretical Economics, 148, pp. $588-606$.

Butz, David A. (1996), Does the per se rule deter vertical price-fixing?, Economic Inquiry, 34 (4), pp. 770-780.

Chevalier, Judith and Austan Goolsbee (2003), Price competition online: Amazon versus Barnes and Noble, Quantitative Marketing and Economics, 1 (2), pp. 203-222.

Clay, Karen B., Ramayya Krishnan and Eric D. Wolff (2001), Prices and price dispersion on the web: evidence from the online book industry, Journal of Industrial Economics, 49 (4), pp. 521-539.

Clerides, Sofronis K. (2001), Product selection with multi-peaked preferences in book publishing, mimeo.

- (2002), Book value: intertemporal pricing and quality discrimination in the U.S. market for books, International Journal of Industrial Organization, 20 (10), pp. 1385-1408.

Deneckere, Raymond, Dan Kovenock and Robert Lee (1992), A model of price leadership based on consumer loyalty, Journal of Industrial Economics, 40 (2), pp. 147-156.

Deneckere, Raymond, Howard P. Marvel and James Peck (1996), Demand uncertainty, inventories, and resale price maintenance, Quarterly Journal of Economics, 111 (3), pp. 885-913.

- (1997), Demand uncertainty and price maintenance: markdowns as destructive competition, American Economic Review, 87 (4), pp. 619-641.

Evans, William N. and Robert M. Schwab (1995), Finishing high school and starting college: do catholic schools make a difference?, Quarterly Journal of Economics, 110 (4), pp. 941-974. 
Fabbri, Daniele, Chiara Monfardini and Rosalba Radice (2004), Testing exogeneity in the bivariate probit model: Monte Carlo evidence and an application to health economics, mimeo.

Feenstra, Robert C. and James Levinsohn (1995), Estimating markups and market conduct with multidimensional product attributes, Review of Economic Studies, 62, pp. 1952.

Goyder, Daniel G. (1998), EC Competition Law (Oxford University Press), 3rd edition.

Greene, William H. (2003), Econometric analysis (Prentice Hall, Upper Saddle River, NJ).

Guillebraud, C. W. (1965), The Marshall-Macmillan correspondence over the net book system, Economic Journal, 75, pp. 518-538.

Heckman, James J. (1978), Dummy endogenous variables in a simultaneous equation system, Econometrica, 46 (6), pp. 931-959.

- (1979), Sample selection bias as a specification error, Econometrica, 47 (1), pp. 153-161.

Holly, Alberto, Lucien Gardiol, Gianfranco Domenighetti and Brigitte Bisig (1998), An econometric model of health care utilization and health insurance in Switzerland, European Economic Review, 42, pp. 513-522.

Ivaldi, Marc, Bruno Jullien, Patrick Rey, Paul Seabright and Jean Tirole (2003), The economics of tacit collusion, final report for DG competition, European Commission.

Jullien, Bruno and Patrick Rey (2000), Resale price maintenance and collusion, cEPR Discussion Paper, London.

Kandel, Eugene (1996), The right to return, Journal of Law E Economics, 39, pp. 329-356.

Knittel, Christopher R. and Victor Stango (2003), Price ceilings as focal points for tacit collusion: evidence from credit cards, American Economic Review, 93 (5), pp. 1703-1729.

Liefmann, R. (1904), Der deutsche Buchhandel in der Kartellenquete, nebst Untersuchungen über seine Organisation und seine voraussichtliche Weiterbildung, Jahrbücher für Nationalökonomie und Statistik, 28 (3), pp. 200-237. 
Maddala, G. S. (1983), Limited-Dependent and Qualitative Variables in Econometrics (Cambridge University Press).

Martin, Stephen (1993), Advanced industrial economics (Blackwell Publishers).

Maskin, Eric and Jean Tirole (1988), A theory of dynamic oligopoly, II: price competition, kinked demand curves, and edgeworth cycles, Econometrica, 56 (3), pp. 571-599.

Mathewson, Frank and Ralph Winter (1998), The law and economics of resale price maintenance, Review of Industrial Organization, 13, pp. 57-84.

Mehta, Judith, Chris Starmer and Robert Sugden (1994), The nature of salience: an experimental investigation of pure coordination games, American Economic Review, 84 (3), pp. 658-673.

OECD (1997), Resale price maintenance (Proceedings, Roundtables on Competition Policy).

Ornstein, Stanley I. and Dominique M. Hanssens (1987), Resale price maintenance: output increasing or restricting? The case of distilled spirits in the United States, Journal of Industrial Economics, 36 (1), pp. 1-18.

Picot, Arnold (1991), Comment on W. Breit, Resale price maintenance: what do economists know and when did they know it?, Journal of Institutional and Theoretical Economics, 147, pp. 91-96.

Pohle, L. (1895), Das deutsche Buchhändlerkartell, Schriften des Vereins für Socialpolitik, 61, pp. 459-532.

Rabassa, Valerie (2001), The Commission's review of the media merger wave, Competition policy newsletter, 2001 (1), pp. 46-51.

Rotemberg, Julio J. and Garth Saloner (1990), Collusive price leadership, Journal of Industrial Economics, 39 (1), pp. 93-111.

Salop, Steven and Joseph Stiglitz (1977), Bargains and ripoffs: a model of monopolistically competitive price dispersion, Review of Economic Studies, 44 (3), pp. 493-510.

Schelling, Thomas (1963), The strategy of conflict (Oxford University Press). 
Scherer, Frederic M. and David Ross (1990), Industrial market structure an economic performance (Houghton Mifflin), 3rd edition.

Stumpp, Henning (1998), Die Preisbindung für Verlagserzeugnisse: Wettbewerbsbeschränkung oder Regulierung zur Beseitigung von Marktunvollkommenheiten? (Nomos, Baden-Baden).

Sugden, Robert (1995), A theory of focal points, The Economic Journal, 105, pp. 533-550.

Symeonidis, George (2002), Cartel stability with multiproduct firms, International Journal of Industrial Organization, 20, pp. 339-352.

Telser, Lester (1960), Why would manufacturers want fair trade?, Journal of Law E Economics, 3, pp. 86-105.

Tosdal, Harry R. (1915), Price maintenance in the book trade, Quarterly Journal of Economics, 30 (1), pp. 86-109.

van der Ploeg, Frederick (2004), Beyond the dogma of the fixed book price agreement, Journal of Cultural Economics, 28, pp. 1-20.

Varian, Hal R. (1980), A model of sales, American Economic Review, 70 (4), pp. 651-659.

Wang, Hao (2004), Resale price maintenance in an oligopoly with uncertain demand, International Journal of Industrial Organization, 22, pp. 389-411.

Wilde, Joachim (2000), Identification of multiple equation probit models with endogenous regressors, Economics Letters, 69, pp. 309-312.

Wooldridge, Jeffrey M. (2002), Econometric Analysis of Cross Section and Panel Data (MIT Press, Cambridge, MA).

Yamey, Basil S. (1954), The origins of resale price maintenance: A study of three branches of retail trade, Economic Journal, 62 (247), pp. 522-545. 


\section{A Theoretical framework: explicit results and simulation}

Simulation of price distribution for hypothetical benchmark. I simulated the distribution for 1000 titles' prices when pricing is according to equation 2, with respective $r_{i}$ uniformly distributed over [0;2] and $n_{i}$ uniformly distributed over [0;1]. This requires a slight reinterpretation of $m$ : here, it is the number of switchers undecided between a given pair out of these 1000 titles. $^{30}$ The resulting price distribution is presented in the form of a histogram (figure 4).

Figure 4: Simulated price distribution, assuming benchmark case

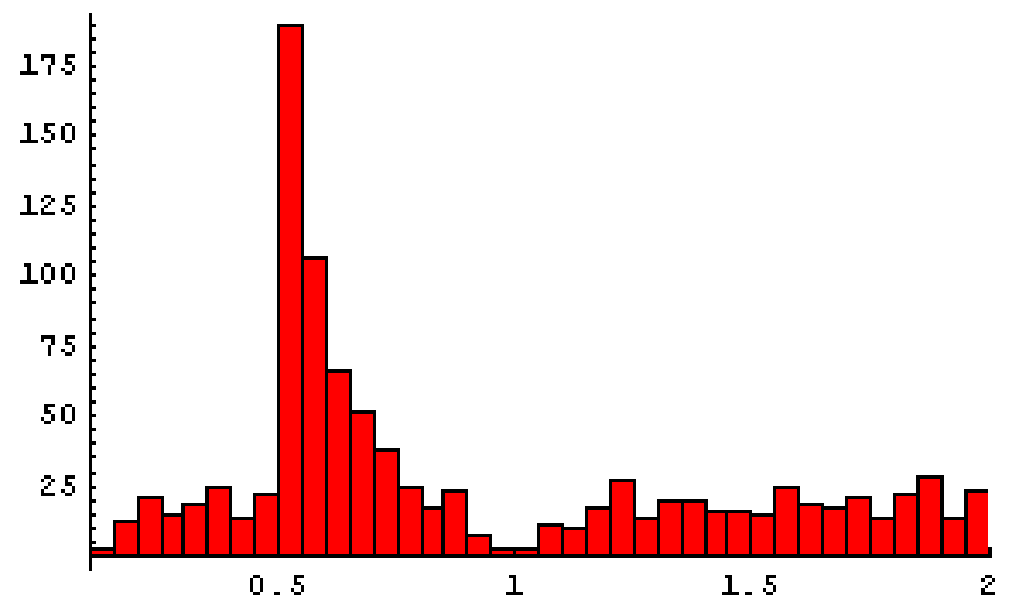

Explicit results for $r^{\min }$ and $r^{\max }$ in equation 4. In order to find $r^{\min }$, the publisher compares the expected profit from focal pricing which ignores loyal consumers $\left(p=p^{f}>r\right)$ with that from setting $p=r<p^{f}$. In the first case, she gets $(1-q) p^{f}\left(1-p^{f}\right)+q p^{f}:=$ $\pi_{0}^{F}\left(p^{f}, q\right)$. In the latter case she gets $(1-q) r(1-r+n)+q r(1+n)$, which is smaller than $\pi_{0}^{F}$ if

$$
r \leq r^{\min }=\frac{1+n}{2(1-q)}-\frac{\sqrt{(1+n)^{2}-4(1-q) \pi_{0}^{F}}}{2(1-q)} .
$$

In case $r>p^{f}, r^{\max }$ is the upper bound for $r$ above which it is more profitable to focus only on loyal consumers (with $p=r$ ) than to price focally:

$$
\begin{aligned}
& r n>(1-q) p^{f}\left(1-p^{f}+n-1\right)+q p^{f}(1+n) \\
\Leftrightarrow & \quad r>r^{\max }=p^{f} \frac{(1+n-(1-q) q)}{n}
\end{aligned}
$$

\footnotetext{
${ }^{30}$ Under the normalization $m=1$, the total number of switchers in this simulated market is thus $\frac{1000}{2}$.
} 
Explicit results for $n^{\min }, n^{\max }, \bar{q}$ and $\bar{r}$ in equation 4. In some cases, for example if $p^{f}$ and/or $q$ are not very large, it may be profitable to price above $p^{f}$ by choosing $\bar{p}=\frac{1+n-q}{2(1-q)}$. However, this is feasible only if $\bar{p}$ is (1) lower than one, this is the case if $n<n^{\max }=1-q$, and (2) higher than $p^{f}$, this is the case if $n>(1-q)\left(2 p^{f}-1\right)$ (hence for all $n$ if $p^{f}<\frac{1}{2}$ ). It is profitable only if it yields more profit than setting $p=p^{f}$ or $p=r$. Suppose $n, q$ and $p^{f}$ are such that $\bar{p}$ is feasible. The resulting expected profit is $\frac{(1+n-q)^{2}}{4(1-q)}$. It is better than setting $p=r>\bar{p}$ if

$$
\begin{gathered}
r n<\frac{(1+n-q)^{2}}{4(1-q)} \\
\Leftrightarrow \quad r<\bar{r}=\frac{(1+n-q)^{2}}{4 n(1-q)} .
\end{gathered}
$$

Comparing the expected profit for $p=\bar{p}$ with that from focal pricing (see above), we get conditions on $q$ and $n$ for which setting $p=\bar{p}$ is more profitable than focal pricing:

$$
\begin{aligned}
q<\bar{q} & =\frac{2\left(1-p^{f}\right)^{2}}{2-3 p^{f}+2\left(p^{f}\right)^{2}} \\
n>n^{\text {min }} & =(1-q)\left(2 p^{f}-1\right)+q+\sqrt{4 p^{f}(1-q) q .}
\end{aligned}
$$

Hence, it pays to set $p=\bar{p}$ different from $p^{f}$ and $r$ only if $q<\bar{q}, n^{\text {min }}<n<n^{\text {max }}$ and $\left(p^{f}<\right) \bar{p} \geq r<\bar{r}$. If $q<\bar{q}$ and $n^{\text {min }}<n<n^{\text {max }}$ but $p^{f}<r<\bar{p}$, it is optimal to set $p=r$ since the respective profit function is increasing in $p$.

Assessing stability by simulation. I simulated a price distribution for 1000 titles with respective $r_{i}$ uniformly distributed over [0;2] and $n_{i}$ uniformly distributed over [0;1], for three focal point candidates and differing values of $q$. In all three cases, an iterative procedure replacing the previously found empirical value for $q$ converged to a stable $q$ independent of the value used in the initial simulation. For $p^{f}=\frac{1}{2}$, the resulting distribution of prices is in this sense stable for $q=0.71$, has a mean of about 0.88 and is depicted in figure $5:^{31}$

\footnotetext{
${ }^{31}$ Notice that $q$ cannot be directly obtained from these histograms, since they give the frequencies over the whole range of prices, while for calculation of $q$ one has to relate only those in the range $[0 ; 1]$ to the number of titles on $p^{f}$.
} 
Figure 5: Simulated focal price distribution for $p^{f}=\frac{1}{2}$ and $q=0.71$

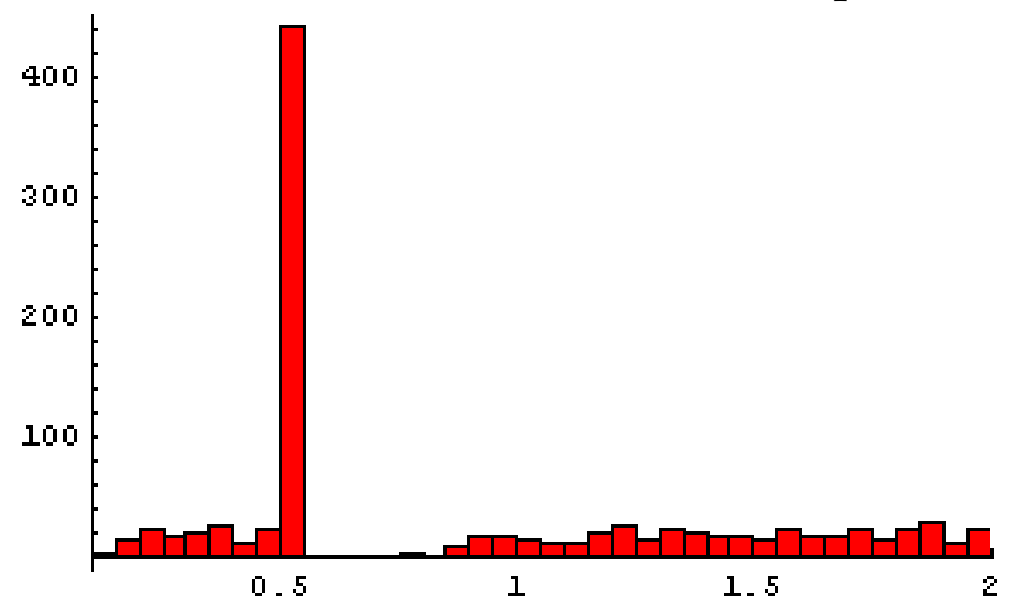

The resulting price distribution for $p^{f}=\frac{3}{4}$ is stable for $q=0.63$, has a mean of about 0.9 and is depicted in figure 6 :

Figure 6: Simulated focal price distribution for $p^{f}=\frac{3}{4}$ and $q=0.63$

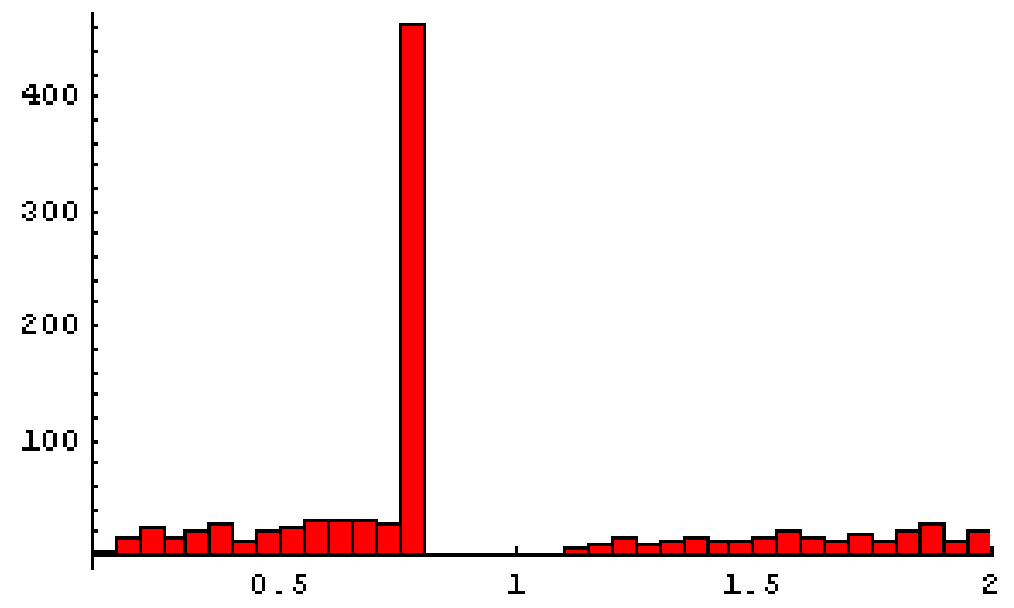

The resulting price distribution for $p^{f}=1$ is stable for $q=0.51$, has a mean of about 1 and is depicted in figure 7: 
Figure 7: Simulated focal price distribution for $p^{f}=1$ and $q=0.51$

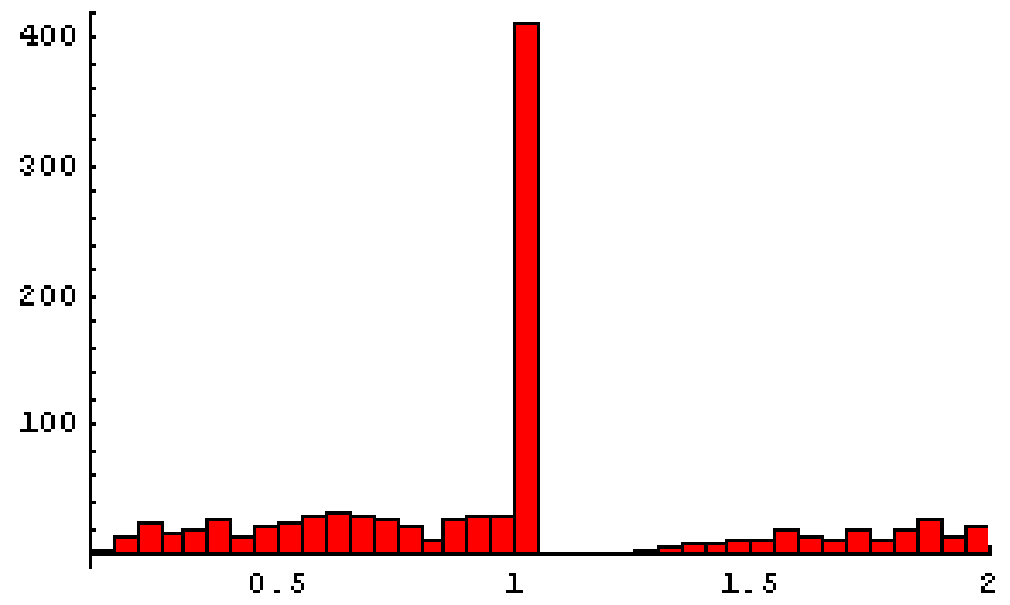

\section{B Hedonic regression: variables and coefficient estimates}

Table 9: Description of explanatory variables

\begin{tabular}{|c|c|}
\hline Variable & Description \\
\hline $\begin{array}{l}\text { Pages } \\
\text { dBlackImg } \\
\text { dColorImg } \\
\text { dRepr } \\
\text { dSeries }\end{array}$ & $\begin{array}{l}\text { Number of pages } \\
=1 \text { if title has black\&white images, figures, or tables (zero else) } \\
=1 \text { if title has colored images, figures, or tables (zero else) } \\
=1 \text { if title is a reprint (zero else) } \\
=1 \text { if title is published as part of a series (zero else) }\end{array}$ \\
\hline \multicolumn{2}{|c|}{$\begin{array}{l}\text { Fixed effects: } \\
21 \text { types of binding, } 3 \text { years of publication (1999-2001), } \\
130 \text { 3-digit segments, } 1643 \text { publishers }\end{array}$} \\
\hline $\begin{array}{l}\text { Interaction } \\
\text { Pages }^{2}, d B\end{array}$ & $\begin{array}{l}\text { of the above variables used in estimation: } \\
\text { kImg*Pages, } d \text { ColorImg*Pages }\end{array}$ \\
\hline
\end{tabular}


Table 10: Summary statistics on explanatory variables - popular segments

\begin{tabular}{|c|c|c|c|c|}
\hline \multirow[t]{3}{*}{ Segment/Variable } & \multicolumn{4}{|c|}{ Mean (std. dev.) by 1-digit segment and focality } \\
\hline & \multicolumn{2}{|c|}{ Hardcover } & \multicolumn{2}{|c|}{ Paperback } \\
\hline & $d F O C A L=0$ & $d F O C A L=1$ & $d F O C A L=0$ & $d F O C A L=1$ \\
\hline \multicolumn{5}{|l|}{ Fiction } \\
\hline Pages & $\begin{array}{r}323.10 \\
(263.35)\end{array}$ & $\begin{array}{r}320.60 \\
(149.97)\end{array}$ & $\begin{array}{r}231.60 \\
(21661)\end{array}$ & $\begin{array}{r}183.52 \\
(135.99)\end{array}$ \\
\hline dBlackImg & 0.04 & 0.03 & 0.19 & 0.25 \\
\hline dColorImg & 0.01 & 0.02 & 0.10 & 0.14 \\
\hline dRepr & 0.12 & 0.11 & 0.09 & 0.11 \\
\hline dSeries & 0.91 & 0.90 & 0.27 & 0.26 \\
\hline \multicolumn{5}{|l|}{ Kids/Youth } \\
\hline Pages & $\begin{array}{r}178.15 \\
(117.93)\end{array}$ & $\begin{array}{l}145.32 \\
(71.98)\end{array}$ & $\begin{array}{r}92.29 \\
(92.99)\end{array}$ & $\begin{array}{r}87.12 \\
(73.50)\end{array}$ \\
\hline dBlackImg & 0.10 & 0.22 & 0.13 & 0.13 \\
\hline dColorImg & 0.12 & 0.09 & 0.40 & 0.42 \\
\hline$d R e p r$ & 0.09 & 0.11 & 0.13 & 0.13 \\
\hline dSeries & 0.67 & 0.59 & 0.27 & 0.39 \\
\hline \multicolumn{5}{|l|}{ Travel } \\
\hline Pages & $\begin{array}{r}331.64 \\
(197.21)\end{array}$ & $\begin{array}{r}253.25 \\
(111.88)\end{array}$ & $\begin{array}{r}213.83 \\
(161.18)\end{array}$ & $\begin{array}{r}201.93 \\
(129.33)\end{array}$ \\
\hline dBlackImg & 0.43 & 0.25 & 0.32 & 0.29 \\
\hline dColorImg & 0.34 & 0.58 & 0.54 & 0.56 \\
\hline dRepr ${ }^{\circ}$ & 0.39 & 0.47 & 0.25 & 0.27 \\
\hline dSeries & 0.80 & 0.88 & 0.42 & 0.49 \\
\hline \multicolumn{5}{|l|}{ Nonfiction } \\
\hline Pages & 282.46 & 217.03 & 210.13 & 152.47 \\
\hline & (1231.34) & (97.15) & (370.17) & (119.38) \\
\hline dBlackImg & 0.17 & 0.09 & 0.29 & 0.27 \\
\hline dColorImg & 0.07 & 0.02 & 0.39 & 0.43 \\
\hline$d R e p r$ & 0.18 & 0.19 & 0.21 & 0.15 \\
\hline dSeries & 0.84 & 0.93 & 0.31 & 0.24 \\
\hline
\end{tabular}


Table 11: Summary statistics on explanatory variables - professional segments

\begin{tabular}{|c|c|c|c|c|}
\hline \multirow[t]{3}{*}{ Segment/Variable } & \multicolumn{4}{|c|}{ Mean (std. dev.) by 1-digit segment and focality } \\
\hline & \multicolumn{2}{|c|}{ Hardcover } & \multicolumn{2}{|c|}{ Paperback } \\
\hline & $d F O C A L=0$ & $d F O C A L=1$ & $d F O C A L=0$ & $d F O C A L=1$ \\
\hline \multicolumn{5}{|l|}{ Humanities } \\
\hline \multirow[t]{2}{*}{ Pages } & 307.60 & 227.86 & 299.53 & 257.75 \\
\hline & (365.40) & (115.06) & $(267.19)$ & $(154.88)$ \\
\hline dBlackImg & 0.21 & 0.22 & 0.28 & 0.29 \\
\hline dColorImg & 0.04 & 0.03 & 0.13 & 0.19 \\
\hline dRepr & 0.20 & 0.21 & 0.11 & 0.13 \\
\hline dSeries & 0.85 & 0.92 & 0.43 & 0.28 \\
\hline \multicolumn{5}{|c|}{ Science/Technology/Medicine } \\
\hline \multirow[t]{2}{*}{ Pages } & 279.61 & 233.99 & 346.05 & 280.79 \\
\hline & (180.08) & (112.25) & (285.78) & $(187.57)$ \\
\hline dBlackImg & 0.28 & 0.28 & 0.50 & 0.32 \\
\hline dColorImg & 0.05 & 0.02 & 0.12 & 0.21 \\
\hline dRepr & 0.23 & 0.12 & 0.28 & 0.18 \\
\hline dSeries & 0.70 & 0.79 & 0.39 & 0.47 \\
\hline \multicolumn{5}{|l|}{ Social Sciences/Law } \\
\hline \multirow[t]{2}{*}{ Pages } & 302.11 & 226.78 & 315.91 & 276.80 \\
\hline & (173.11) & (148.62) & (285.13) & (157.15) \\
\hline dBlackImg & 0.15 & 0.09 & 0.18 & 0.23 \\
\hline dColorImg & 0.01 & 0.02 & 0.02 & 0.04 \\
\hline$d \operatorname{Repr}$ & 0.26 & 0.20 & 0.22 & 0.14 \\
\hline dSeries & 0.85 & 0.93 & 0.56 & 0.56 \\
\hline \multicolumn{5}{|l|}{ School/Learning } \\
\hline \multirow[t]{2}{*}{ Pages } & 145.23 & 126.50 & 159.24 & 98.47 \\
\hline & (96.32) & (71.61) & $(134.71)$ & $(62.48)$ \\
\hline dBlackImg & 0.19 & 0.01 & 0.29 & 0.35 \\
\hline dColorImg & 0.04 & 0.03 & 0.12 & 0.07 \\
\hline$d \operatorname{Repr}$ & 0.30 & 0.42 & 0.30 & 0.16 \\
\hline dSeries & 0.94 & 0.99 & 0.15 & 0.16 \\
\hline
\end{tabular}

Interpretation of results (table 12). Across the sample, the marginal effect of the number of Pages on the hedonic price is positive and increases for titles with black\&white images (dBlackImg) as well as for titles with colored images (dColorImg), with one exception (professional hardcovers). For example, ten additional pages are estimated to increase a popular hardcover's price by on average $1.2 \%$ for a title without images, by $1.5 \%(1.2+0.3)$ for a title with black\&white images, and by $2.1 \%(1.2+0.9)$ for a title with colored images. The image dummies themselves predominantly have negative and insignificant coefficients, which at first seems counterintuitive. However, these estimates may be due to demand heterogeneities across 3-digit segments. For example, in the segment of popular hardcovers, colored images may be fairly standard for children books while uncommon in adult fiction. Since children books generally have lower prices, this may be partly 
Table 12: Hedonic regression results

\begin{tabular}{|c|c|c|c|c|}
\hline \multirow[b]{2}{*}{ Segment: } & \multicolumn{4}{|c|}{ Dependent variable: $\ln$ (price) } \\
\hline & $\begin{array}{l}\text { Popular } \\
\text { hardcover }\end{array}$ & $\begin{array}{l}\text { Popular } \\
\text { paperback }\end{array}$ & $\begin{array}{l}\text { Professional } \\
\text { hardcover }\end{array}$ & $\begin{array}{c}\text { Professional } \\
\text { paperback }\end{array}$ \\
\hline $\begin{array}{l}\text { Coefficient estimates: } \\
\text { pages }\end{array}$ & $\begin{array}{l}0.0012^{*} \\
(0.0001)\end{array}$ & $\begin{array}{l}0.0008^{*} \\
(0.0001)\end{array}$ & $\begin{array}{c}0.0013^{*} \\
(0.00003)\end{array}$ & $\begin{array}{l}0.0015^{*} \\
(0.0001)\end{array}$ \\
\hline dblackimg & $\begin{array}{l}-0.0151 \\
(0.0260)\end{array}$ & $\begin{array}{l}-0.1558^{*} \\
(0.0337)\end{array}$ & $\begin{array}{l}-0.0013 \\
(0.0142)\end{array}$ & $\begin{array}{l}-0.1283^{*} \\
(0.0392)\end{array}$ \\
\hline dcolorimg & $\begin{array}{l}-0.0363 \\
(0.0292)\end{array}$ & $\begin{array}{l}-0.0694 \\
(0.0465)\end{array}$ & $\begin{array}{c}0.0494 \\
(0.0257)\end{array}$ & $\begin{array}{l}-0.1928^{*} \\
(0.0808)\end{array}$ \\
\hline dBlackImg*Pages & $\begin{array}{l}0.0003^{*} \\
(0.0001)\end{array}$ & $\begin{array}{l}0.0007^{*} \\
(0.0001)\end{array}$ & $\begin{array}{c}0.00003 \\
(0.00004)\end{array}$ & $\begin{array}{l}0.0004^{*} \\
(0.0001)\end{array}$ \\
\hline dColorImg*Pages & $\begin{array}{l}0.0009^{*} \\
(0.0002)\end{array}$ & $\begin{array}{l}0.0008^{*} \\
(0.0001)\end{array}$ & $\begin{array}{l}-0.0001 \\
(0.0001)\end{array}$ & $\begin{array}{l}0.0006^{*} \\
(0.0003)\end{array}$ \\
\hline pagSQ & $\begin{array}{l}-1.09 \mathrm{e}-7^{*} \\
(1.30 \mathrm{e}-8)\end{array}$ & $\begin{array}{l}-1.95 e-8^{*} \\
(3.61 \mathrm{e}-9)\end{array}$ & $\begin{array}{l}-7.8 \mathrm{e}-8^{*} \\
(8.11 \mathrm{e}-9)\end{array}$ & $\begin{array}{l}-1.34 \mathrm{e}-7^{*} \\
(1.3 \mathrm{e}-8)\end{array}$ \\
\hline dRepr & $\begin{array}{l}-0.0338^{*} \\
(0.0096)\end{array}$ & $\begin{array}{c}0.0185 \\
(0.0153)\end{array}$ & $\begin{array}{l}-0.1502^{*} \\
(0.0060)\end{array}$ & $\begin{array}{l}-0.1474^{*} \\
(0.0157)\end{array}$ \\
\hline dSeries & $\begin{array}{l}-0.1606^{*} \\
(0.0090)\end{array}$ & $\begin{array}{l}-0.0472^{*} \\
(0.0223)\end{array}$ & $\begin{array}{l}-0.0064 \\
(0.0050)\end{array}$ & $\begin{array}{c}0.0419 \\
(0.0322)\end{array}$ \\
\hline \multicolumn{5}{|l|}{ Fixed effects (number): } \\
\hline $\begin{array}{l}\text { Dinaing aummies } \\
\text { Years of publication }\end{array}$ & $\begin{array}{c}21 \\
3\end{array}$ & $\begin{array}{c}21 \\
3\end{array}$ & $\begin{array}{c}21 \\
3\end{array}$ & $\begin{array}{c}21 \\
3\end{array}$ \\
\hline 2-digit segments & 32 & 31 & 35 & 32 \\
\hline Publishers & 1195 & 188 & 1315 & 191 \\
\hline Observations & 23312 & 6025 & 48609 & 3641 \\
\hline$R^{2}$ & 0.73 & 0.65 & 0.75 & 0.80 \\
\hline Adjusted $R^{2}$ & 0.71 & 0.64 & 0.74 & 0.79 \\
\hline \multicolumn{5}{|c|}{$\begin{array}{l}\text { Note: OLS estimation results for focal price definition Top3. } \\
\text { Heteroskedasticity-consistent standard errors in parentheses. } \\
\text { Starred coefficients are significant at the } 95 \% \text { confidence level. }\end{array}$} \\
\hline
\end{tabular}

picked up in the coefficient for colored images. Except in popular paperback segments, reprints (dRepr) enjoy a significant discount ranging from 3.4 to $15 \%$ on average, which signifies the existence of economies of scale in production. Titles published within a Series are significantly cheaper only in the two groups of popular segments. 


\section{Simultaneous probit: alternative specifications}

Table 13: Bivariate probit results for restricted FOCAL equation

\begin{tabular}{lrrrr}
\hline & \multicolumn{2}{c}{ Popular hardcovers } & \multicolumn{2}{c}{ Popular paperbacks } \\
& Coefficient & Std. error & Coefficient & Std. error \\
\hline FOCAL equation: & & & & \\
dRPM & $1.6090^{*}$ & $(0.4068)$ & -1.1895 & $(0.9437)$ \\
FipCatShare & $2.4571^{*}$ & $(0.3987)$ & $3.8687^{*}$ & $(0.7860)$ \\
CompCatShare & $57.9328^{*}$ & $(8.0126)$ & $32.2305^{*}$ & $(5.5833)$ \\
Constant & $-6.2857^{*}$ & $(0.4256)$ & $-2.2728^{*}$ & $(1.0000)$ \\
\hline RPM equation: & & & & \\
dSeries & -0.1480 & $(0.1047)$ & 0.6888 & $(0.4397)$ \\
$p$ DistNeg & $-0.5211^{*}$ & $(0.1230)$ & 0.2584 & $(0.4323)$ \\
pDistPos & -0.1904 & $(0.1331)$ & -0.6375 & $(0.3829)$ \\
PubSize & $0.2328^{*}$ & $(0.0436)$ & $0.4544^{*}$ & $(0.0733)$ \\
SgtSize & $0.1109^{*}$ & $(0.0471)$ & $0.3575^{*}$ & $(0.1255)$ \\
Constant & -0.3133 & $(0.3365)$ & $-3.2559^{*}$ & $(1.0437)$ \\
\hline$\hat{\rho}$ & $-0.5331^{*}$ & & 0.2548 & \\
Log-likelihood & -13370.14 & & -3286.80 & \\
Observations & 36352 & & 13096 & \\
No. of publishers & 1195 & & 189 & \\
\hline
\end{tabular}

Note: Standard errors are robust to within-cluster (publisher) correlation. Starred coefficients are significant at the $95 \%$ confidence level. 
Table 14: Bivariate probit results for restricted RPM equation

\begin{tabular}{|c|c|c|c|c|}
\hline & \multicolumn{2}{|c|}{ Popular hardcovers } & \multicolumn{2}{|c|}{ Popular paperbacks } \\
\hline & Coefficient & Std. error & Coefficient & Std. error \\
\hline $\begin{array}{l}\text { FOCAL equation: } \\
d R P M\end{array}$ & $1.4506^{*}$ & $(0.3702)$ & -0.3156 & $(0.5985)$ \\
\hline pDistNeg & 0.0332 & $(0.1689)$ & 0.4302 & $(0.4298)$ \\
\hline pDistPos & 0.2998 & $(0.3897)$ & $1.2424^{*}$ & $(0.4792)$ \\
\hline FipCatShare & $2.5403^{*}$ & $(0.4223)$ & $4.1302^{*}$ & $(0.8932)$ \\
\hline CompCatShare & $60.5889^{*}$ & $(9.5625)$ & $38.1277^{*}$ & (7.9605) \\
\hline$d D o m F i$ & $1.3500^{*}$ & $(0.4264)$ & $3.0763^{*}$ & $(0.6369)$ \\
\hline$d$ FringeFi & 0.1248 & $(0.1461)$ & 0.1773 & $(0.2599)$ \\
\hline Constant & $-6.5083^{*}$ & $(0.5519)$ & $-3.8579^{*}$ & $(0.9840)$ \\
\hline RPM equation: & & & & \\
\hline dSeries & -0.1415 & $(0.1026)$ & 0.6844 & $(0.4321)$ \\
\hline PubSize & $0.2216^{*}$ & $(0.0434)$ & $0.4679^{*}$ & $(0.0664)$ \\
\hline SgtSize & $0.1205^{*}$ & $(0.0460)$ & $0.3489^{*}$ & $(0.1198)$ \\
\hline Constant & -0.4295 & $(0.3307)$ & $-3.3094^{*}$ & (1.0837) \\
\hline$\hat{\rho}$ & $-0.4813^{*}$ & & 0.1450 & \\
\hline Log-likelihood & -13186.57 & & -3013.32 & \\
\hline Observations & 36352 & & 13096 & \\
\hline No. of publishers & 1195 & & 189 & \\
\hline
\end{tabular}

Note: Standard errors are robust to within-cluster (publisher) correlation. Starred coefficients are significant at the $95 \%$ confidence level. 
Bücher des Forschungsschwerpunkts Markt und politische Ökonomie

Books of the Research Area Markets and Political Economy

Pablo Beramendi

Decentralization and Income Inequality

2003, Madrid: Juan March Institute

Thomas Cusack

A National Challenge at the Local Level: Citizens, Elites and Institutions in Reunified Germany

2003, Ashgate

Sebastian Kessing

Essays on Employment Protection

2003, Freie Universität Berlin,

http://www.diss.fu-berlin.de/2003/202

Daniel Krähmer

On Learning and Information in Markets and

Organizations

2003, Shaker Verlag

Bob Hancké

Large Firms and Institutional Change. Industrial Renewal and Economic Restructuring in France 2002, Oxford University Press

Andreas Stephan

Essays on the Contribution of Public Infrastruc-

ture to Private: Production and its Political

Economy

2002, dissertation.de

Peter A. Hall, David Soskice (Eds.)

Varieties of Capitalism

2001, Oxford University Press

Hans Mewis

Essays on Herd Behavior and Strategic Delegation

2001, Shaker Verlag

Andreas Moerke

Organisationslernen über Netzwerke - Die

personellen Verflechtungen von Führungsgremien

japanischer Aktiengesellschaften

2001, Deutscher Universitäts-Verlag

Silke Neubauer

Multimarket Contact and Organizational Design

2001, Deutscher Universitäts-Verlag

Lars-Hendrik Röller, Christian Wey (Eds.)

Die Soziale Marktwirtschaft in der neuen

Weltwirtschaft, WZB Jahrbuch 2001

2001, edition sigma

Michael Tröge

Competition in Credit Markets: A Theoretic

Analysis

2001, Deutscher Universitäts-Verlag

Torben Iversen, Jonas Pontusson, David Soskice

(Eds.)

Unions, Employers, and Central Banks

2000, Cambridge University Press
Tobias Miarka

Financial Intermediation and Deregulation:

A Critical Analysis of Japanese Bank-Firm-

Relationships

2000, Physica-Verlag

Rita Zobel

Beschäftigungsveränderungen und

organisationales Lernen in japanischen

Industriengesellschaften

2000, Humboldt-Universität zu Berlin

http://dochost.rz.hu-berlin.de/dissertationen/zobel-rita2000-06-19

Jos Jansen

Essays on Incentives in Regulation and Innovation 2000, Tilburg University

Ralph Siebert

Innovation, Research Joint Ventures, and Multiproduct Competition

2000, Humboldt-Universität zu Berlin

http://dochost.rz.hu-berlin.de/dissertationen/siebert-

ralph-2000-03-23/

Damien J. Neven, Lars-Hendrik Röller (Eds.)

The Political Economy of Industrial Policy in

Europe and the Member States

2000, edition sigma

Jianping Yang

Bankbeziehungen deutscher Unternehmen:

Investitionsverhalten und Risikoanalyse

2000, Deutscher Universitäts-Verlag

Christoph Schenk

Cooperation between Competitors -

Subcontracting and the Influence of Information, Production and Capacity on Market Structure and Competition

1999, Humboldt-Universität zu Berlin

http://dochost.rz.hu-berlin.de/dissertationen/schenkchristoph-1999-11-16

Horst Albach, Ulrike Görtzen, Rita Zobel (Eds.)

Information Processing as a Competitive

Advantage of Japanese Firms

1999, edition sigma

Dieter Köster

Wettbewerb in Netzproduktmärkten

1999, Deutscher Universitäts-Verlag

Christian Wey

Marktorganisation durch Standardisierung: Ein

Beitrag zur Neuen Institutionenökonomik des

Marktes

1999, edition sigma 
Annette Boom

Kai A. Konrad Wolfram F. Richter

Stergios Skaperdas

Johan Lagerlöf

Roman Inderst

Christian Wey

Sebastian Kessing

Robert Nuscheler

Lars Frisell

Paul Heidhues

Nicolas Melissas

Pablo Beramendi

Daniel Krähmer

Ralph Siebert

Vivek Ghosal

Vivek Ghosal

Andreas Blume

Paul Heidhues

Sebastian Kessing

Tomaso Duso Astrid Jung

Thomas R. Cusack Pablo Beramendi

Kjell Erik Lommerud Frode Meland Odd Rune Straume Joseph Clougherty
Investments in Electricity Generating Capacity under Different Market Structures and with Endogenously Fixed Demand

Zur Berücksichtigung von Kindern bei umlagefinanzierter Alterssicherung

Restraining the Genuine Homo Economicus: Why the Economy cannot be divorced from its Governance

Insisting on a Non-Negative Price: Oligopoly, Uncertainty, Welfare, and Multiple Equilibria

Buyer Power and Supplier Incentives

Monopoly Pricing with Negative Network Effects: The Case of Vaccines

The Breakdown of Authority

Equilibria in a Dynamic Global Game: The Role of Cohort Effects

Political Institutions and Income Inequality: The Case of Decentralization

Learning and Self-Confidence in Contests

The Introduction of New Product Qualities by Incumbent Firms: Market Proliferation versus Cannibalization

Impact of Uncertainty and Sunk Costs on Firm Survival and Industry Dynamics

Endemic Volatility of Firms and Establishments: Are Real Options Effects Important?

Private Monitoring in Auctions

Delay in Joint Projects

Product Market Competition and Lobbying Coordination in the U.S. Mobile

Telecommunications Industry

Taxing Work: Some Political and Economic Aspects of Labor Income Taxation

Globalisation and Union Opposition to Technological Change

Industry Trade-Balance and Domestic Merger Policy: Some Empirical Evidence from the U.S.
SP || $2003-14$

SP || $2003-01$

SP || $2003-02$

SP II $2003-03$

SP || $2003-04$

SP II $2003-05$

SP || $2003-06$

SP || $2003-07$

SP || $2003-08$

SP || $2003-09$

SP || $2003-10$

SP || $2003-11$

SP || $2003-12$

SP || $2003-13$

SP || $2003-15$

SP || $2003-16$

SP || $2003-17$

SP || $2003-18$

SP || $2003-19$ 
Dan Anderberg Fredrik Andersson

Eugenio J. Miravete Lars-Hendrik Röller

Talat Mahmood Klaus Schömann

Talat Mahmood Klaus Schömann

Suchan Chae Paul Heidhues

Sigurt Vitols

Michal Grajek

Kai A. Konrad

Helmut Bester

Kai A. Konrad

Kai A. Konrad

Kai A. Konrad

Steffen Huck Kai A. Konrad
Stratification, Social Networks in the Labour Market, and Intergenerational Mobility

Estimating Markups under Nonlinear Pricing Competition

On the Migration Decision of IT-Graduates:

A Two-Level Nested Logit Model

Assessing the Migration Decision of Indian IT-Graduates: An Empirical Analysis

Buyers Alliances for Bargaining Power

Negotiated Shareholder Value: The German Version of an Anglo-American Practice

Estimating Network Effects and Compatibility in Mobile Telecommunications

Bidding in Hierarchies

Easy Targets and the Timing of Conflict

Opinion Leaders, Influence Activities and Leadership Rents

Mobilität in mehrstufigen Ausbildungsturnieren

Moral Cost, Commitment and Committee Size
SP || $2003-20$

SP || 2003- 21

SP || $2003-22$

SP || $2003-23$

SP || $2003-24$

SP || $2003-25$

SP || $2003-26$

SP || $2003-27$

SP || $2003-28$

SP || $2003-29$

SP || $2003-30$

SP || $2003-31$ 
Jos Jansen

Johan Lagerlöf

Lars Frisell

Sigurt Vitols

Lutz Engelhardt

Antonio Guarino

Steffen Huck

Thomas D. Jeitschko

Thomas Plümper

Vera E. Troeger

Ulrich Kaisera

Pablo Beramendi Thomas R. Cusack

Joseph Clougherty

Joseph Clougherty

Anming Zhang

Roel C.A. Oomen

Robert J. Franzese,Jr. Jude C. Hays

Albert Banal-Estañol Inés Macho-Stadler Jo Seldeslachts

Oz Shy Rune Stenbacka Jonathan Beck
Partial Information Sharing in Cournot Oligopoly

Lobbying, Information Transmission, and Unequal Representation

Changes in Germany's Bank Based Financial System: A Varieties of Capitalism Perspective

Entrepreneurial Business Models in the German Software Industry: Companies, Venture Capital, and Stock Market Based Growth Strategies of the ,Neuer Markt'

Can Fear Cause Economic Collapse?

Insights from an Experimental Study

External Effects of Currency Unions

An Estimated Model of the German Magazine Market

Diverse Disparities: The Politics and Economics of Wage, Market and Disposable Income Inequalities

Antitrust Holdup Source, Cross-National Institutional Variation, and Corporate Political Strategy Implications for Domestic Mergers in a Global Context

Export Orientation and Domestic Merger Policy: Theory and Some Empirical Evidence

Modelling Realized Variance when Returns are Serially Correlated

Modeling International Diffusion: Inferential Benefits and Methodological Challenges, with an Application to International Tax Competition

Mergers, Investment Decisions and Internal Organisation

Price Competition, Business Hours, and Shopping Time Flexibility

Fixed, Focal, Fair? Book Prices Under Optional Resale Price Maintenance

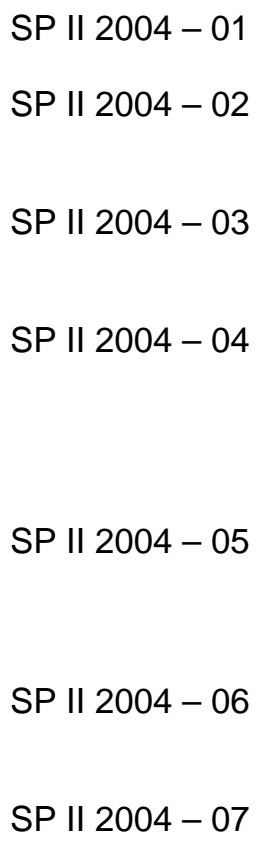

SP II 2004-06 
Bei Ihren Bestellungen von WZB-Papers schicken

Sie bitte unbedingt einen an Sie adressierten Auf-

kleber mit sowie je paper eine Briefmarke im Wert

von 0,51 Euro oder einen "Coupon Reponse Inter-

national " (für Besteller aus dem Ausland)
Please send a self addressed label and postage stamps in the amount of 0.51 Euro or a "CouponReponse International" (if you are ordering from outside Germany) for each WZB-paper requested

Absender I Return Address:

Wissenschaftszentrum Berlin

für Sozialforschung

Presse- und informationsreferat

Reichpietschufer 50

D-10785 Berlin-Tiergarten

Hiermit bestelle ich folgende(s)

Discussion paper(s):

Please send me the following Discussion paper(s):

Bestell-Nr. I Order no.

Autor/in, Kurztitel /Author(s) / Title(s) in brief 